SATISFAÇÃO PROFISSIONAL: PERFIL DOS CIRURGIÕESDENTISTAS QUE EXERCEM SUAS ATIVIDADES EM EMPRESA DO SETOR PRIVADO. SÃO PAULO, 2008 
Teresa Maria da Ponte

\title{
Satisfação profissional: perfil dos cirurgiões-dentistas que exercem suas atividades em empresa do setor
} privado. São Paulo, 2008

\author{
Dissertação apresentada à Faculdade de \\ Odontologia da Universidade de São Paulo, \\ para obter o título de Mestre, pelo Programa de \\ Pós-Graduação em Ciências Odontológicas.
}

Área de Concentração: Odontologia Social

Orientador: Prof. Dr. Edgard Michel Crosato

São Paulo 


\section{FOLHA DE APROVAÇÃO}

Ponte TM. Satisfação profissional: perfil dos cirurgiões-dentistas que exercem suas atividades em empresa do setor privado. São Paulo, 2008 [Dissertação de Mestrado]. São Paulo: Faculdade de Odontologia da USP; 2009.

São Paulo, __ _ _ _ 2009

\section{Banca Examinadora}

1) Prof.(a) Dr.(a)

Titulação:

Julgamento: Assinatura

2) Prof.(a) Dr.(a)

Titulação:

Julgamento: Assinatura

3) Prof.(a) Dr.(a)

Titulação:

Julgamento: Assinatura 


\section{DEDICATÓRIA}

Aos meus pais, Nelson (in memoriam) e Lourdes, que, desde o princípio, foram e continuam sendo a razão de tudo. Obrigada pela vida, o amor, o carinho, o exemplo, os ensinamentos e o apoio incondicional sempre, em todas as minhas escolhas. 


\section{AGRADECIMENTOS}

À Comissão de Pós-Graduação da Universidade de São Paulo.

Ao Prof. Dr. Edgard Michel-Crosato por sua dedicação e exemplo e por acreditar, ensinar, apoiar e realmente orientar-me durante o mestrado.

À Prof. Dra. Maria Gabriela Haye Biazevic pela convivência, amizade e apoio.

Aos Professores do Departamento de Odontologia Social, em especial Maria Ercília de Araújo, Antonio Carlos Frias e Simone Rennó Junqueira, que acompanharam e ainda acompanham meus passos, me motivando sempre.

Às secretárias do Departamento de Odontologia Social, Sônia, Laura e Andréia, pela boa vontade e presteza sempre que precisamos de sua ajuda.

Ao Prof. Danilo Santos de Miranda, a Estanislau da Silva Salles, a Oscar Rodrigues Filho e demais colegas do SESC, pelo incentivo a este trabalho.

Aos amigos Luiz Manoel Moura Magalhães Gomes e Jair de Souza Moreira Júnior pelo apoio e colaboração para a realização deste e de outros projetos.

À equipe de Odontologia e todos os outros amigos que trabalham ou já trabalharam comigo no SESC e nos consultórios.

Aos meus irmãos e irmãs, cunhado, cunhadas, sobrinhos e sobrinhas (lindinhos) que sempre me incentivam e me acompanham em minhas veredas.

Aos amigos mais próximos, que, mesmo quando distantes fisicamente, estão presentes em minha vida.

A todos os cirurgiões-dentistas que aceitaram participar do estudo. 
"A verdadeira filosofia é reaprender a ver o mundo". Maurice Merleau-Ponty 
Ponte TM. Satisfação profissional: perfil dos cirurgiões-dentistas que exercem suas atividades em empresa do setor privado. São Paulo, 2008 [Dissertação de Mestrado]. São Paulo: Faculdade de Odontologia da USP; 2009.

\section{RESUMO}

O objetivo do estudo foi verificar o perfil das atividades profissionais dos cirurgiõesdentistas que desenvolviam suas atividades em uma empresa de caráter privado do Estado de São Paulo. Tratou-se de estudo transversal, realizado por meio de questionário auto-administrado distribuído aos dentistas que trabalhavam em unidades da empresa localizadas em diversas cidades do Estado de São Paulo. A pesquisa foi aprovada pelo Comitê de Ética em Pesquisa da Faculdade de Odontologia da Universidade de São Paulo e foi realizada com ciência e autorização da empresa em questão. Os dados foram organizados e analisados no programa STATA 10.0. Resultados: Participaram da pesquisa 194 cirurgiões-dentistas que exerciam suas atividades na empresa no ano de 2008. Em relação às características sociodemográficas, $68,04 \%$ eram do gênero feminino e 31,96\% do gênero masculino e apresentavam idade entre 25 e 54 anos (média de 35,78 anos). Quanto à formação, 64,43\% estudaram em faculdades públicas e 35,57\% em faculdades particulares; 116 (59,79\%) haviam concluído curso de especialização, 26 (13,40\%), mestrado e 10 (5,15\%) doutorado. O tempo médio de formado foi de 12,85 anos e a média de horas trabalhadas por semana foi de 41,08 horas. Com relação ao acesso a atualizações e produções científicas, $79,38 \%$ relataram ter participado de congresso científico nos últimos dois anos, $87,63 \%$ tinham acesso a revistas científicas e 30,41\% eram membros de alguma sociedade científica. A grande maioria trabalhava em consultório ou clínica particular $(78,35 \%)$ sendo que, entre estes, 32,99\% atendiam convênios. Com relação a outras atividades profissionais, 
30,93\% atuavam também no serviço público e 7,22\% exerciam atividade docente. Apenas 54 profissionais (27,84\%) não apresentaram nenhum problema (dor, desconforto ou dormência) nos braços, mãos, costas ou ombros nos 12 meses anteriores à participação na pesquisa. O nível de satisfação profissional total foi de 3,45 (DP=0,50), considerando-se uma escala de 1 a 5 . Os blocos analisados apresentaram os seguintes valores: satisfação geral com o trabalho: média=3,39, $\mathrm{DP}=0,89$; percepção de renda: média=3,21, $\mathrm{DP}=0,74$; tempo pessoal: média=2,60, $\mathrm{DP}=1,06$; tempo profissional: média=3,13, $\mathrm{DP}=0,71$; equipe: média=3,35, $\mathrm{DP}=0,98$; relacionamento com pacientes: média=4,34, $\mathrm{DP}=0,59$ e fornecimento de assistência/atendimento: média=4,16, $\mathrm{DP}=0,58$. Conclui-se que a maioria dos profissionais que participaram desta pesquisa era do gênero feminino, estudou em faculdade pública, fez curso de especialização, participou de congresso nos 2 anos anteriores, teve acesso a revistas científicas e trabalhava em consultório particular. Também a maior parte $(72,16 \%)$ apresentou alguma dor, desconforto ou dormência nos braços, mãos, costas ou ombros nos 12 meses prévios ao estudo. O nível de satisfação total dos profissionais pôde ser considerado bom, sendo que o bloco que apresentou menor valor de satisfação foi o tempo pessoal. Houve associação de gênero com as variáveis: horas trabalhadas, dor e relacionamento com pacientes e, com relação às horas trabalhadas, houve associação com as variáveis: consultório particular e serviço público; foi observado, ainda, que quanto maior a quantidade de horas dedicadas, maior foi a satisfação com relação à renda e menor com relação ao tempo pessoal.

Palavras-Chave: satisfação no trabalho, força de trabalho, prática profissional, odontologia 
Ponte TM. Job satisfaction: professional activities profile among the dentists who worked in a private enterprise of São Paulo State. São Paulo, 2008 [Dissertação de Mestrado]. São Paulo: Faculdade de Odontologia da USP; 2009.

\section{ABSTRACT}

The objective of the study was to verify professional activities profile among the dentists who worked in a private enterprise of São Paulo State. A descriptive crosssectional and analytic study was carried out, using a self-administered questionnaire distributed to dentists who worked in the company's units located in different cities of São Paulo State. The investigation project was submitted to and approved by the School of Dentistry (FOUSP) Ethical Committee and was done with science and authorization of the participants. Data were organized and analysed at STATA 10.0 statistical package. Participated of the study 194 dentists that were working in the company in year 2008. Regarding sociodemographic characteristics, $68.04 \%$ were female and $31.96 \%$ were male and aged between 25 and 54 years (mean 35.78 years). About professional formation and performance, $64.43 \%$ studied in public schools and 35.57\% in private colleges, 116 (59.79\%) were specialists, $26(13.40 \%)$ had Master's degree and 10 (5.15\%) were PhDs. The mean number of years since dental school graduation was 12.85 years and the mean working hours per week was 41.08 hours. Regarding access to scientific updates, $79.38 \%$ reported having participated in scientific congress in the last two years, $87.63 \%$ had access to scientific journals and $30.41 \%$ were members of a scientific society. Most of them worked also in another private setting (78.35\%) and, between them, $32.99 \%$ attended dental insurance patients in those places. In relation to other professional activities, $30.93 \%$ worked also in the public service and $7.22 \%$ were college professors. Only 54 professionals (27.84\%) did not show any problems (pain, 
discomfort or numbness) in their arms, hands, back or shoulders in the 12 months prior to participation in research. The mean score of overall job satisfaction was 3.45 $(\mathrm{SD}=0.50)$, in a 1 to 5 scale. The blocks of factors examined showed the following values: general satisfaction with job/employment: mean $=3.39, \mathrm{SD}=0.89$; income perception: mean $=3.21, \mathrm{SD}=0.74$; personal time: mean $=2.60, \mathrm{SD}=1.06$; professional time: mean $=3.13, \mathrm{SD}=0.71$; team: mean $=3.35, \mathrm{SD}=0.98$; patients relationship: mean $=4.34, S D=0,59$ and healthcare delivery: mean $=4.16, S D=$ 0.58. The majority of professionals who participated in this study were female, studied in public Universities, were specialists, participated in some conference 2 years earlier, had access to scientific journals and worked in another private practice. Also most of them (72.16\%) has had some pain, discomfort or numbness in the arms, hands, back or shoulders at the some point over the 12 months prior to the study. Job satisfaction levels among the professionals could be considered good, and the block that had the lowest satisfaction was personal time. There was an association between gender and the variables: working hours, pain and patients relationship and, with respect to working hours, it was associated to concurrent attendance at another private healthcare setting and at public service; it was observed also that the greater the amount of working hours, the greater was the satisfaction with respect to income and less the satisfaction with personal time.

Keywords: job satisfaction, work force, work practice, Dentistry 


\section{LISTA DE TABELAS}

Tabela 5.1 Distribuição dos Cirurgiões-Dentistas segundo gênero e região de residência. São Paulo, 2008.

Tabela 5.2 Distribuição dos Cirurgiões-Dentistas segundo idade e anos de formados. São Paulo, 2008

Tabela 5.3 Distribuição dos Cirurgiões-Dentistas segundo tipo de faculdade e cursos de educação continuada realizados. São Paulo, 2008

Tabela 5.4 Distribuição dos Cirurgiões-Dentistas segundo especialização em área básica, clínica ou social. São Paulo, 2008.

Tabela 5.5 Distribuição dos Cirurgiões-Dentistas considerando-se o acesso a atualizações e produções científicas. São Paulo, 2008

Tabela 5.6 Distribuição dos Cirurgiões-Dentistas segundo outras atividades exercidas em odontologia. São Paulo, 2008.......

Tabela 5.7 Distribuição dos Cirurgiões-Dentistas segundo horas trabalhadas por semana, posição de trabalho e pacientes por turno. São Paulo, 2008.

Tabela 5.8 Distribuição dos Cirurgiões-Dentistas segundo posição de trabalho. São Paulo. 2008

Tabela 5.9 Distribuição dos Cirurgiões-Dentistas segundo terem tido 
algum problema como dor, desconforto ou dormência nos últimos 12 meses em braços, mãos, costas e/ou ombros. São Paulo, 2008

Tabela 5.10 Distribuição dos Cirurgiões-Dentistas de acordo com a quantidade de dores, desconforto ou dormência relatados. São Paulo, 2008

Tabela 5.11 Distribuição dos Cirurgiões-Dentistas considerando-se práticas saudáveis. São Paulo, 2008

Tabela 5.12 Distribuição dos Cirurgiões-Dentistas sobre aspectos relativos à gestão em odontologia. São Paulo, 2008.

Tabela 5.13 Distribuição das Cirurgiãs-Dentistas segundo aspectos relativos a participação da mulher na odontologia. São Paulo, 2008

Tabela 5.14 Distribuição dos Cirurgiões-Dentistas segundo satisfação no trabalho. São Paulo, 2008

Tabela 5.15 Relação entre gênero e fatores associados. São Paulo, 2008

Tabela 5.16 Relação entre horas trabalhadas e fatores associados. São Paulo, 2008

Tabela 5.17 Distribuição dos Cirurgiões-Dentistas segundo médias de satisfação no trabalho. São Paulo, 2008 


\section{LISTA DE ABREVIATURAS E SIGLAS}

CD Cirurgião-dentista

CONEP Conselho Nacional de Ética em Pesquisa

DG Dentista generalista

DORT Distúrbios Osteomusculares Relacionados ao Trabalho

DP Desvio Padrão

FOUSP Faculdade de Odontologia da Universidade de São Paulo

INBRAPE Instituto Brasileiro de Estudos e Pesquisas Socioeconômicos

LER Lesões por Esforços Repetitivos

Máx. Valor máximo

Mín. Valor mínimo

RPG Reeducação postural global

SNS Sistema Nacional de Saúde

SPG Satisfação profissional geral 


\section{SUMÁRIO}

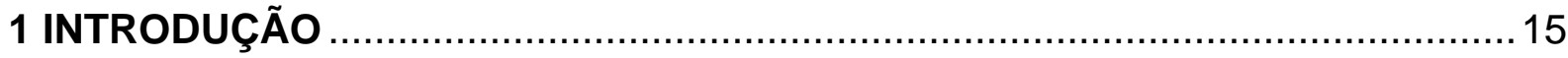

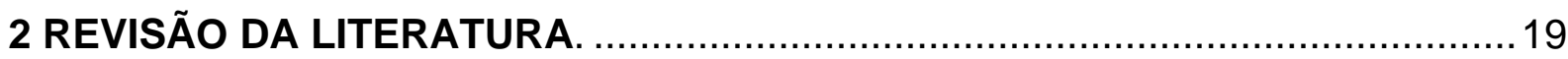

2.1 Características sociodemográficas e atuação profissional ......................19

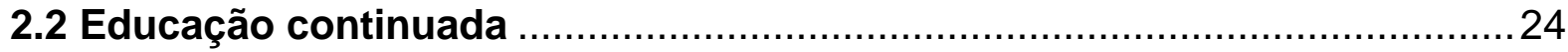

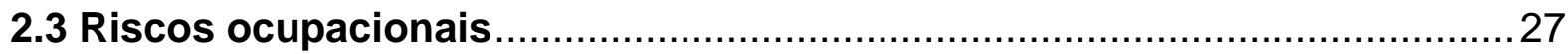

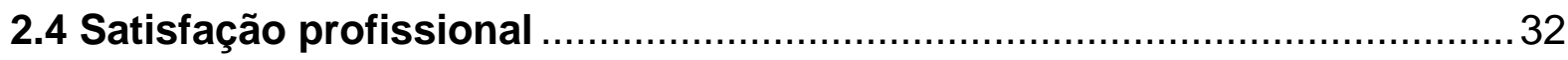

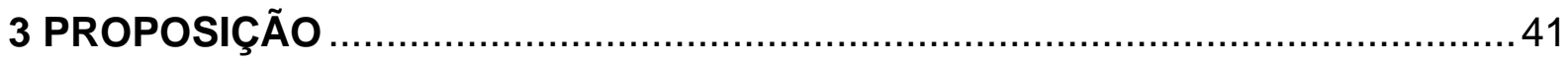

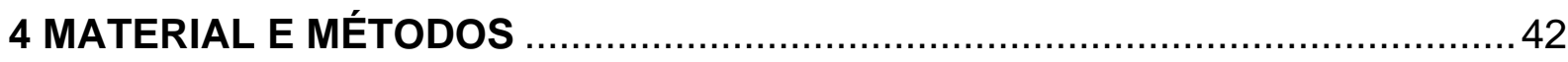

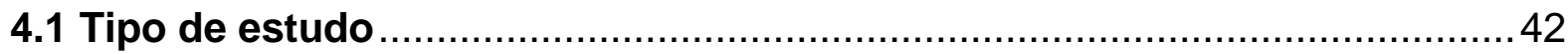

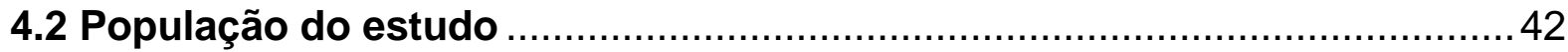

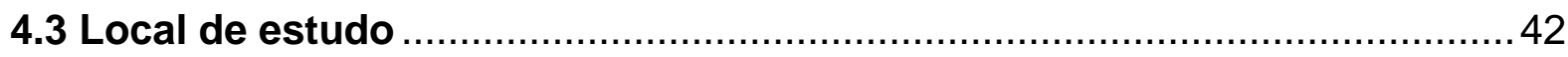

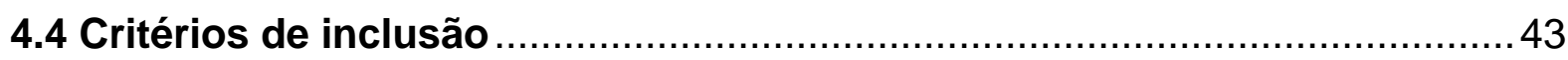

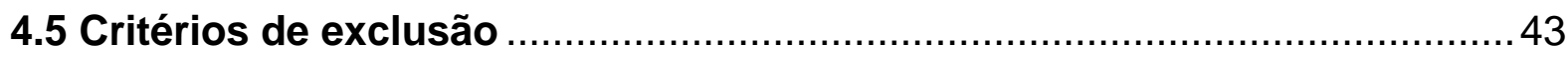

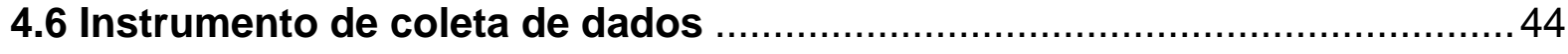

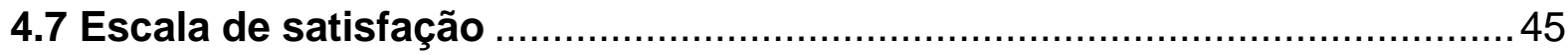

4.8 Método de aplicação do questionário ........................................... 46

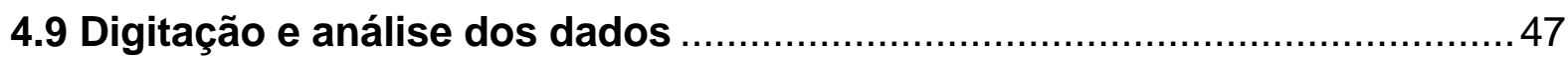

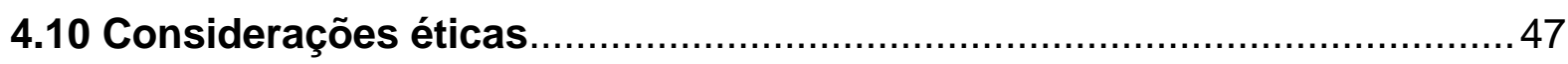

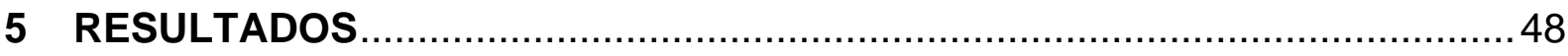

5.1 Distribuição sociodemográfica ..................................................... 48

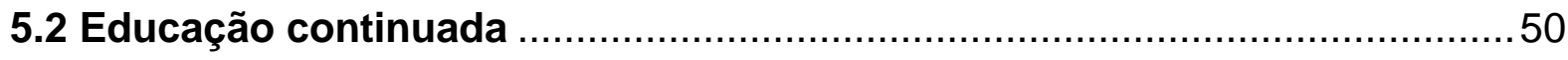

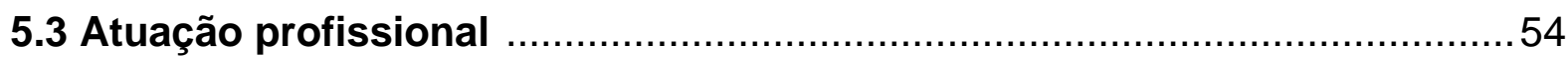




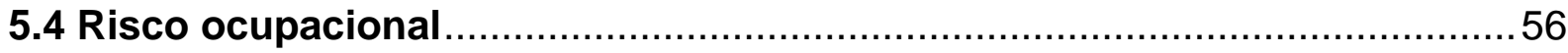

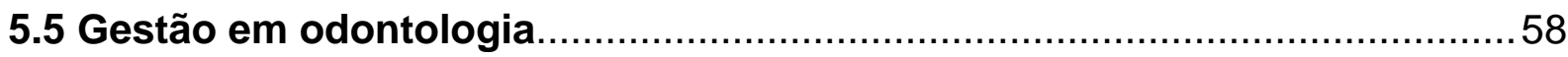

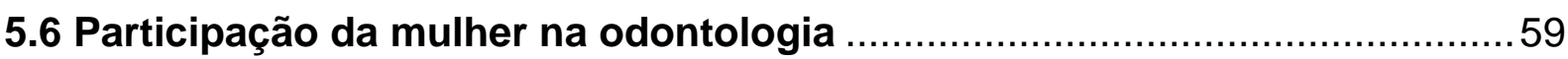

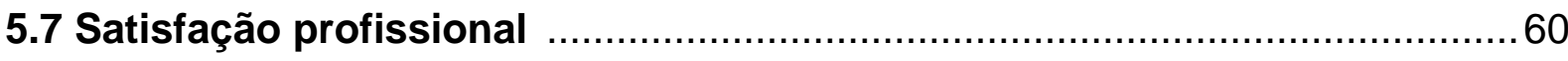

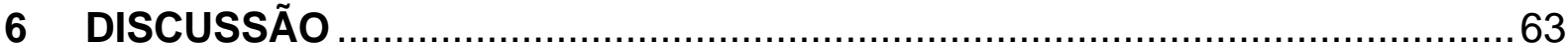

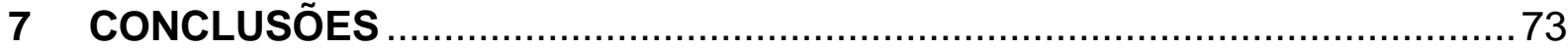

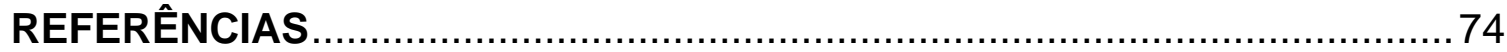

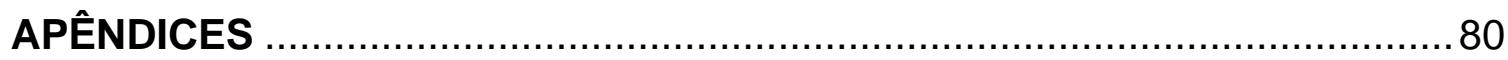

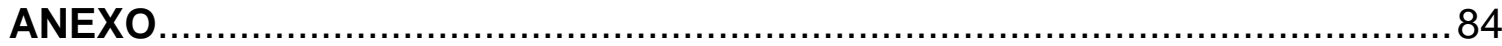




\section{INTRODUÇÃO}

O modelo competente de gestão de pessoas para a atualidade é aquele orientado para solucionar problemas, enfrentar os desafios e apresentar resultados. No campo da saúde e especificamente da odontologia, o gerenciamento do profissional de saúde é fundamental para o êxito dos sistemas de saúde e de saúde bucal (MARZIALE; MENDES, 2006).

Nesse contexto, conhecer o perfil da força de trabalho é a primeira ferramenta para direcionar ações para uma correta política de recursos humanos em saúde e saúde bucal (MICHEL-CROSATO et al., 2003).

Devemos destacar as diferenças existentes entre as expressões recursos humanos e força de trabalho. O termo força de trabalho corresponde à caracterização socioeconômica e demográfica dos profissionais de uma determinada área, suas aspirações, sua visão de mundo e sua percepção com o setor de atuação. Já a expressão recursos humanos é utilizada no âmbito das ciências da administração, e mais especificamente num espectro de gerenciamento. Assim, optamos por adotar, neste trabalho, a nomenclatura força de trabalho, que parecenos mais adequada à descrição e interpretação de uma realidade profissional, o que é nosso foco (SILVA,1994).

Outra definição importante para o presente estudo é o significado da palavra perfil, que pode ser classificado como conjunto de fatores ou itens indicadores das qualidades ou traços característicos de uma pessoa (TOLEDO e MILIONI, 1986). 
Nesse contexto de mudanças, é importante conhecer as características atuais da profissão existente em um país, em um determinado momento, sabendo que são resultantes do processo evolutivo dessa atividade e caracterizam uma etapa de evolução da profissão. Assim, para tentar verificar em que estágio encontra-se a odontologia e, como conseqüência, caracterizar o mercado de trabalho dessa profissão em nosso país, é necessário conhecer a força de trabalho existente no momento (PINTO, 2008).

A prática de uma profissão não pode ser considerada somente como o resultado das aptidões e habilidades de sua força de trabalho. Ela irá resultar da confluência de fatores psicológicos e sociais que exercem marcada influência sobre o comportamento do homem no exercício de sua profissão e condicionam a compatibilização do profissional com seu trabalho. O nível de ajustamento do profissional nos leva à chamada satisfação profissional (KOLTIANRENKO, 2005).

Nos estudos sobre satisfação profissional, entre os fatores mais comumente analisados verificamos a satisfação geral com o trabalho, a percepção de renda, o tempo pessoal, o tempo profissional, equipe, relacionamento com pacientes e fornecimento de assistência/atendimento (BARAN, 2005; GILMOUR et al., 2005; JEONG et al., 2006; LUZZI et al., 2005; MYERS; MYERS, 2004; PURIENE et al., 2007; ROTH et al., 2003).

Há diversos tipos de questionários e escalas utilizados para tentar mensurar o nível de satisfação profissional, como os utilizados nos trabalhos realizados por Gilmour et al. (2005), Gorter et al. (2006), Harris et al. (2008), Harris e Zwane (2005), Hjalmers (2006), Jeong et al. (2006), Luzzi et al. (2005), Puriene et al. (2007), Roth et al. (2003), entre outros. 
Vários estudos também têm sido realizados no intuito de verificar as características de atendimento dos serviços de saúde bucal. A maioria destes evidencia que os profissionais escolhem como opção o consultório privado e os profissionais do gênero masculino têm melhores rendimentos, além do fato de trabalharem mais horas por semana (AYERS et al., 2008; BRENNAN; SPENCER; SZUSTER, 2000; CÓRDON, 1991; COSTA, 1988; MADEIRA; PERRI DE CARVALHO, 1980; NEWTON; THOROGOOD; GIBBONS, 2000; POURAT et al., 2007).

Além de consultórios particulares, serviço no setor público e atividade docente, outra opção para o profissional odontológico é o trabalho em empresas do setor privado.

O mercado de trabalho odontológico não pode ser considerado promissor, devido a fatores como o número excessivo de profissionais, a abertura indiscriminada de novas faculdades e à má-distribuição dos profissionais no território nacional. Em contrapartida, os cirurgiões-dentistas, principalmente os formados há mais tempo, começam a apresentar boa satisfação profissional, em relação a aspectos como o retorno financeiro, as horas dedicadas ao trabalho em Odontologia, o relacionamento com o paciente e com a equipe de trabalho (MICHEL-CROSATO, 2008).

Apesar das dificuldades encontradas no exercício profissional, há aspectos satisfatórios e promissores no campo da Odontologia. Para que se saiba mais sobre o mercado de trabalho, é fundamental conhecer as características dos profissionais que atuam na área, seu perfil, suas práticas e condições de trabalho, assim como sua satisfação profissional. Por meio desse conhecimento, poderão ser programadas e implementadas políticas de formação e inserção profissional que 
favoreçam o preparo adequado para a prática no panorama atual e levem à expansão de condições favoráveis à maior qualidade de vida dos cirurgiõesdentistas e, consequentemente, de seus pacientes. 


\section{REVISÃO DA LITERATURA}

Optamos por apresentar a revisão de literatura de forma diferente da tradicional, não por data de publicação, mas por temas, a fim de favorecer a leitura.

\subsection{Características sociodemográficas e atuação profissional}

Muitos são os fatores potencialmente importantes a serem verificados para o conhecimento mais profundo do perfil e da prática profissional de cirurgiõesdentistas.

Bengmark, Nilner e Rohlin (2007) descreveram algumas características de graduados das cinco primeiras turmas do programa odontológico de Malmö (Suécia). Quanto à situação atual, a maioria dos participantes estava trabalhando como dentista em período integral e acreditava que seu curso tinha fornecido uma boa base para o exercício da profissão.

No estudo de Gorter et al. (2008), a amostra foi estratificada por gênero, idade e região. Um total de 632 dentistas com idade média de 44,6 anos respondeu à pesquisa, sendo a amostra constituída 75\% de homens e 25\% de mulheres.

Nos estudos sobre atuação e satisfação profissionais, um dos pontos a serem destacados são as diferenças nas práticas de trabalho que podem estar associadas a vários fatores. 
Na pesquisa de Blasius e Pae (2005) notou-se que, entre ortodontistas, os padrões de trabalho de homens e mulheres diferiam de alguma forma, mas essas diferenças podiam não ser tão significantes quanto outros fatores; são necessários mais estudos. Profissionais que trabalhavam sozinhos eram predominantes na área de ortodontia, independentemente da idade e sexo.

Os autores del Aguila et al. (2005) não encontraram diferenças entre dentistas homens e mulheres com relação ao número de procedimentos por paciente. As distribuições de freqüência de vários serviços foram extremamente similares para ambos os grupos, concluindo-se que os padrões da prática de dentistas homens e mulheres em geral foram equivalentes na população do Serviço Odontológico de Washington estudada. Quanto às implicações clínicas, constatou-se que dentistas mulheres e homens ofereciam uma gama/quantidade similar de serviços.

Outros aspectos importantes abordados no estudo do exercício profissional de cirurgiões-dentistas são as horas dedicadas ao trabalho (carga horária), os períodos de afastamento e a renda auferida.

Michel-Crosato et al. (2003), em estudo realizado para verificar o perfil do egresso do curso de odontologia da Faculdade de Odontologia da Universidade de São Paulo (FOUSP), observaram diferenças de horas dedicadas conforme o tempo de formado do profissional. Em relação ao número de horas que o cirurgião-dentista dedicava à odontologia no primeiro ano após a formatura, 189 (59,62\%) cirurgiõesdentistas relataram atuar além de 8 horas por dia. Quanto maior o tempo de formado, maior foi a porcentagem de profissionais que trabalhavam de 8 a 12 horas e menor a quantidade dos que trabalhavam menos de 8 horas diárias. 
Em pesquisa realizada utilizando-se questionário aplicado a ortodontistas, Blasius e Pae (2005) observaram que o número de filhos pareceu ser um bom preditor para o número de dias trabalhados por semana e para a duração de licenças por dentistas mulheres. Mulheres não proprietárias do consultório/clínica apresentaram maior tendência a períodos mais longos de ausência por licença e, no geral, todas trabalhavam um pouco menos dias por semana e dedicavam um pouco menos de horas ao atendimento direto a pacientes. Anualmente, elas dedicavam 25 dias a menos que os homens à prática profissional, mas, quando ajustados para períodos de ausência, homens e mulheres trabalharam um número equivalente de semanas em 1999.

Com resultados parecidos aos do estudo descrito acima, na pesquisa de del Aguila et al. (2005) os números das médias e medianas de dias trabalhados foram cerca de $10 \%$ mais baixas para dentistas mulheres que homens. Esta diferença foi consistente com o achado que dentistas mulheres atendiam 10\% menos pacientes, realizavam cerca de $10 \%$ menos procedimentos, e tinham uma renda conjugada de $10 \%$ menos que os dentistas homens. Além desses fatos, constatou-se que mulheres trabalhavam menos dias por ano que os homens, independente da idade. Os autores não encontraram diferenças entre dentistas homens e mulheres com relação à renda por paciente ou renda por dia de trabalho. Modelos de regressão múltipla mostraram que não havia influência do sexo dos profissionais na renda total.

Em pesquisa realizada na África do Sul, Naidoo (2005), notou que apesar de uma maioria significativa das cirurgiãs-dentistas estar exercendo a profissão (96\%), cerca de $20 \%$ estavam empregadas ou trabalhavam meio-período e 7 relataram que não estavam exercendo a profissão na época da pesquisa por várias razões, 
incluindo licença maternidade, má saúde, aposentadoria ou porque estavam trabalhando em outra área.

Seguindo a mesma tendência, no estudo de Ayers et al. (2008), sobre dentistas neozelandeses de ambos os gêneros, foi constatado que as mulheres trabalhavam menos horas por semana e sua principal razão para o trabalho de meio-período foi cuidar dos filhos, enquanto que para os homens foi a escolha pessoal. Observou-se também que mais mulheres que homens interromperam por algum tempo suas atividades profissionais, geralmente para criarem os filhos. Dois terços das profissionais do sexo feminino contra um terço dos do sexo masculino planejaram se aposentar antes dos 60 anos.

A opção por ser proprietário de consultório ou trabalhar como contratado em algum serviço e as práticas relativas ao trabalho em equipe são outros fatores importantes a serem pesquisados para se conhecer mais a fundo as dinâmicas do exercício profissional dos cirurgiões-dentistas.

O estudo de Blasius e Pae (2005) constatou que apesar das mulheres (ortodontistas americanas) terem uma tendência menor que os homens a serem proprietárias de consultório, apenas $20 \%$ delas responderam que não estavam em posição de proprietárias. Os autores também constataram que, no grupo estudado, as mulheres apresentaram um pouco mais de tendência a estarem envolvidas em uma prática de grupo, trabalhavam em menos consultórios/clínicas que os homens e empregavam menos pessoal auxiliar em tempo integral ou parcial.

Dados similares foram obtidos por Ayers et al. (2008), onde uma proporção maior de mulheres que homens era assalariada ou sócia de clínica, ao invés de possuir seu próprio consultório. 
Avaliando outra característica do trabalho em equipe, estudando o apoio percebido, Berthelsen, Hjalmers e Söderfeldt (2008) avaliaram de que maneira dentistas dinamarqueses generalistas de clínicas particulares percebiam o apoio de colegas e relacionaram o apoio percebido a fatores contextuais demográficos e relacionados ao trabalho. A variável mais importante relacionada à percepção de apoio entre dentistas foi o tamanho da clínica. As mulheres perceberam maior apoio emocional (por exemplo, discutindo com suas colegas sobre pacientes problemáticos) que seus colegas homens; por outro lado, não foi encontrada diferença de gênero para a percepção de apoio prático, como ajudar um ao outro no caso de atraso nos horários.

Muitos estudos evidenciam as dificuldades da mulher no exercício da profissão e como este fator pode afetar sua qualidade de vida, portanto estes também são aspectos importantes a serem enfatizados.

Moimaz, Saliba e Blanco (2003), estudando a força de trabalho feminino em Araçatuba - São Paulo, verificaram que a maioria das profissionais vivenciava dupla jornada, ou seja, a rotina de cuidados no consultório e em casa; 37\% relataram ter diminuído sua carga horária após o nascimento dos filhos; $44 \%$ relataram que a renda obtida não era compatível com suas necessidades básicas; 87\% afirmaram que não eram a principal fonte de renda da família e 50,5\% declararam possuir algum tipo de problema de saúde ocasionado pela atuação profissional, com maior freqüência dores na coluna e varizes.

Em Naidoo (2005), os fatores mais importantes identificados foram as responsabilidades dobradas das mulheres, em casa e no trabalho. Responsabilidades em casa e condições inflexíveis de trabalho foram dificuldades comumente relatadas e comprovadas por outros estudos. O autor considera que 
mulheres dentistas precisam de horários de trabalho e condições de emprego mais flexíveis e que opções de treinamento e carreira de meio-período deveriam ser ampliadas; também sugere que cursos de aperfeiçoamento e atualização para dentistas mulheres que tiveram uma interrupção na carreira deveriam estar disponíveis para prepará-las para voltarem ao trabalho de forma mais rápida e fácil.

Hjalmers, em 2006, realizou um estudo com cirurgiãs-dentistas suecas, tendo como objetivo verificar quais eram os problemas que estas sofriam em decorrência de seu exercício profissional e em dois artigos publicados sobre o estudo, Hjalmers (2006) e Hjalmers, Söderfeldt e Axtelius (2006), os autores relatam que as profissionais sofriam com muitos problemas relacionados às suas condições psicossociais de trabalho e que existem grandes discrepâncias entre sua percepção de situação ideal de trabalho e a sua realidade.

Ayers et al. (2008) encontrou diferença significativa entre as médias de pontuação de satisfação na carreira para homens e mulheres $(p<0.001)$.

\subsection{Educação continuada}

Educação continuada não é um conceito novo, mas nestes últimos anos vem ganhando especial relevância, tendo em vista as recentes transformações no mundo do trabalho e no conjunto da sociedade. A educação continuada é aquela que se 
realiza ao longo da vida, continuamente, é inerente ao desenvolvimento do ser humano e relaciona-se com a idéia de construção deste ser. Abarca, de um lado, a aquisição de conhecimentos e aptidões e, de outro, atitudes e valores, implicando no aumento da capacidade de discernir e agir. A idéia de educação continuada associase à própria característica distintiva dos seres humanos, a capacidade de conhecer e querer saber mais, ultrapassando o plano puramente instintivo de sua relação com o mundo e com a natureza (HADDAD, 2007).

Nos estudos sobre as atividades profissionais desenvolvidas pelos cirurgiõesdentistas e satisfação profissional, a educação continuada merece destaque. Geralmente as pesquisas abordam questões relativas às intenções de realização ou à conclusão de cursos de aperfeiçoamento, especialização, mestrado e doutorado.

Os resultados e a análise de dados recolhidos pelo questionário-pesquisa aplicado aos graduandos de cursos de Odontologia pelo Exame Nacional de Cursos ("Provão") foram divulgados no site do Instituto Nacional de Estudo e Pesquisa Educacionais (2000). Grande parte dos recém-formados revelou um desejo bastante elevado pela continuidade dos estudos: $77,2 \%$ pretendiam fazer cursos de aperfeiçoamento e de especialização e $20 \%$ tinham a intenção de fazer cursos de mestrado e doutorado. Entre as 14 especialidades arroladas, a dentística restauradora foi a que teve o maior índice de adesões, obtendo manifestação de interesse por parte de $59,9 \%$ dos pesquisados.

Estudando a força do trabalho feminino em Odontologia em Araçatuba, Moimaz, Saliba e Blanco (2003), observaram que apenas 15\% das participantes não haviam realizado nenhum curso de pós-graduação. A especialização foi o curso com maior expressividade (75\% das profissionais haviam realizado), seguida de cursos de aperfeiçoamento (48\%). 
$\mathrm{Na}$ pesquisa realizada por Bastos et al. (2003) com graduados de 1996 a 2000 da Faculdade de Odontologia de Bauru da Universidade de São Paulo, 66,3\% dos profissionais fizeram ou estavam fazendo pós-graduação: em nível de aperfeiçoamento/especialização $(52,3 \%)$, mestrado $(47,7 \%)$ e, em número menor, doutorado (7,7\%). Os profissionais, em sua maioria $(69,4 \%)$ consideravam indispensável fazer cursos de pós-graduação, pelas seguintes razões: por ser uma tendência de mercado (44,1\%) por levar ao aprimoramento técnico-científico $(33,8 \%)$, porque melhora a qualificação profissional $(17,6 \%)$ e porque promove uma melhoria no atendimento clínico (14,7\%).

Dos 297 cirurgiões-dentistas entrevistados por Cabral, Caldas e Cabral (2005), 65\% relataram ter realizado alguma pós-graduação.

Naidoo (2005) verificou que poucas cirurgiãs-dentistas sul-africanas exerciam alguma especialidade, apesar de $68 \%$ delas terem indicado que gostariam de ter cursado alguma especialização.

Em pesquisa realizada em 2006 com cirurgiões-dentistas do Meio Oeste Catarinense, Michel-Crosato, Koltiarenko e Biazevic (2006) encontraram as seguintes porcentagens: $76,00 \%$ dos profissionais eram especialistas e $26,00 \%$ clínicos gerais.

O estudo de Jeong et al. (2006) realizado na Coréia do Sul demonstrou que 47\% dos profissionais obtinham título de mestre ou doutor e cerca de um terço (36\%) haviam concluído algum curso de especialização.

Entre os cirurgiões-dentistas de Campina Grande - Paraíba, pesquisados por D'Ávila et al. (2007), 53,3\% eram especialistas e 6,7\% concluíram curso de mestrado ou doutorado. 
Bengmark, Nilner e Rohlin (2007), descrevendo algumas características de graduados das cinco primeiras turmas do programa odontológico de Malmö (Suécia), relataram que, quanto ao gênero, houve diferença com relação ao interesse por atividades de pesquisa: $64 \%$ das mulheres graduadas e $42 \%$ dos homens estavam interessados. Concluiu-se que a maioria gostaria de prosseguir seus estudos na pós-graduação. Já em Ayers et al. (2008), os homens eram mais ativos com relação à educação continuada.

\subsection{Riscos ocupacionais}

Qualquer prática profissional apresenta algum grau de risco ocupacional, que pode ser definido como a susceptibilidade de se adquirirem hábitos, posturas e moléstias advindas da profissão (PERNAMBUCO, 2001) ou, segundo outros autores, como a possibilidade de perda ou dano e a probabilidade de que tal perda ou dano ocorra, implicando, pois, a probabilidade de ocorrência de um evento adverso (BRASIL, 2006).

O trabalho odontológico requer dos seus executores ações que exigem coordenação motora, raciocínio, discernimento, paciência, segurança, habilidade, delicadeza, firmeza, objetividade, ações essas que, em conjunto, exigem muito do profissional. Os riscos mais freqüentes a que estão sujeitos os profissionais que atuam em assistência odontológica são os físicos, os químicos, os ergonômicos, os mecânicos ou de acidente, os advindos da falta de conforto e higiene e os biológicos (PERNAMBUCO, 2001). 
Além dos anteriormente citados, diversos outros fatores referentes à organização do trabalho, tais como a falta de flexibilidade e a alta intensidade do ritmo de trabalho, a execução de grande quantidade de movimentos repetitivos, a sobrecarga de determinados grupos musculares, a ausência de controle sobre o modo e ritmo de trabalho, a ausência de pausas e a exigência de produtividade, entre outros, têm sido apontados como responsáveis pelo aumento do número de lesões por esforços repetitivos (LER) e distúrbios osteomusculares relacionados ao trabalho (DORT) em vários campos profissionais (BRASIL, 2001), inclusive na área odontológica.

As dores nas costas, decorrentes de má postura ocupacional, atormentam um grande número de cirurgiões-dentistas (CD) em todo o mundo. Pesquisas informam que um entre dois CD apresenta patologias na coluna lombar relacionadas à postura profissional. O CD movimenta a coluna no sentido de inclinações para frente, laterais, flexões e extensões. O uso abusivo de uma dessas posições leva a defeitos de origem postural como escoliose, cifose e lordose (PERNAMBUCO, 2001).

Michelin e Loureiro (2000) obtiveram como resultados em seu trabalho com cirurgiões-dentistas uma alta prevalência de distúrbios osteomusculares e evidenciaram a estreita relação entre os distúrbios que acometem os profissionais e sua rotina de atividades. Afirmaram que isso comprova a necessidade de alerta à classe odontológica quanto à preocupaçäo a ser dispensada à sua saúde, pois negligenciando-a, o cirurgiäo-dentista poderá afetar sobremaneira o seu desempenho profissional, bem como a sua qualidade de vida.

Santos Filho e Barreto (2001), em pesquisa realizada em Minas Gerais, obtiveram os seguintes achados: quase a metade dos dentistas relatou que a dor costuma levar à interrupção da sua atividade no trabalho, com alguma freqüência 
(45\% às vezes e $3 \%$ sempre). Além disso, em $57 \%$ dos casos a dor levou a modificações nas rotinas de trabalho, lazer ou limitações da vida diária, como realização de cuidados pessoais e dirigir automóveis. Vinte e três por cento dos dentistas com dor apresentavam história de afastamento do trabalho por causa da dor, dentre estes, 39\% por mais de 15 dias. Mais da metade dos indivíduos sintomáticos (55\%) haviam procurado assistência médica e 23\% haviam utilizado medicamento por causa da dor no último mês; $31 \%$ informaram outro tipo de tratamento.

Pesquisa de Pereira et al. (2004) se propôs a investigar os DORT entre os cirurgiões-dentistas de São Luís - Maranhão. Foram aplicados 140 questionários e os resultados mostraram uma alta frequência de DORT entre aqueles profissionais, com maior incidência na Endodontia. A região lombar foi a mais afetada e foi evidenciado que a avaliação médica havia sido procurada por muitos profissionais. A maioria dos profissionais com DORT relataram uma carga horária semanal de trabalho de 40 horas ou mais. A posição de trabalho sentada e de $11 \mathrm{~h}$ foi a mais comum.

Quanto à presença de sintomatologia dolorosa nas áreas do corpo, muitos estudos apontam o maior acometimento da região do pescoço (BARBOSA et al., 2004; LOPES et al., 2003; SANTOS FILHO; BARRETO, 2001). Ainda estes e outros autores (LOPES et al., 2003; SANTANA, 1998; SANTOS FILHO; BARRETO, 2001) relataram, que, além do pescoço, as regiões mais acometidas são ombro e coluna lombar, sendo grande a variação nas taxas de acometimento entre os cirurgiões-dentistas.

Na pesquisa de Myers e Myers (2004) a quantidade constatada de dor nas costas também foi alta (relatada por $68,3 \%$ dos dentistas). 
Estudo conduzido na Grécia por Alexopoulos, Stathi e Charizani (2004) evidenciou elevada prevalência de queixas músculo-esqueléticas nos 430 cirurgiõesdentistas que participaram da pesquisa mediante a aplicação de um questionário. Os resultados mostraram que $62,00 \%$ dos profissionais relataram ao menos uma queixa dolorosa, $30,00 \%$ sofriam do problema cronicamente, $16,00 \%$ tinham tido relatos de ausência de dor e 32,00\% declararam ter procurado assistência médica por causa dos problemas.

Achados de pesquisa desenvolvida no Meio Oeste Catarinense (MICHELCROSATO; KOLTIARENKO; BIAZEVIC, 2006) também demonstraram uma alta prevalência de distúrbios osteomusculares e este fato foi associado a algumas características ocupacionais e socioeconômicas. Com relação à posição ergonômica de trabalho, as localizações que correspondem a 9,10,11 e 12h foram as preferidas por cerca de $56,86 \%$ dos profissionais e $80 \%$ relataram trabalhar exclusivamente na posição sentado. Dos profissionais, 93\% relataram dores músculo-esqueléticas em pelo menos metade do corpo no último ano em decorrência da atividade profissional e houve predominância para as mulheres. O risco de dor para indivíduos que apresentam probabilidade positiva para transtornos psiquiátricos menores foi cerca de quatro vezes maior e a região com maior prevalência de sintomatologia foi a coluna cervical $(69,93 \%)$.

Dos cirurgiões-dentistas que participaram da pesquisa de Regis Filho, Michels e Sell (2006), 437 (56,68\%) responderam que sim ao serem inquiridos se apresentavam alguma manifestação dolorosa nos membros superiores, cintura escapular ou pescoço, em virtude da repetição de um mesmo padrão de movimento no exercício da profissão. 
Realizou-se estudo de corte transversal com o objetivo de estimar a prevalência de dor musculoesquelética em cirurgiões-dentistas em 21 municípios da Bahia e identificar possíveis fatores de risco à ocorrência destas desordens. Os resultados mostraram prevalência de dor para parte superior das costas, pescoço, parte inferior das costas, ombro e mão/punho, considerando-se o lado direito; e prevalência de dor na parte superior das costas, pescoço e parte inferior das costas do lado esquerdo (GRAÇA; ARAÚJO; SILVA, 2006).

Alguns autores afirmam que a ginástica laboral vem se mostrando como um dos grandes aliados para prevenção de DORT quando executadas de forma a propiciar o alongamento e fortalecimento dos grupamentos musculares utilizados na realização das tarefas e aconselham a recorrer à fisioterapia preventiva ao menor sinal de dor, pois esta também é uma grande aliada na prevenção de DORT (TEREBINTO, 2003).

Frazão (2000) afirma que o profissional deve organizar de forma mais racional o fluxo de atendimento aos pacientes, os procedimentos a serem realizados e praticar um programa de condicionamento físico (ginástica laboral). Também é aconselhável reservar um pequeno intervalo entre as consultas a fim de relaxar os músculos e aliviar as tensões inerentes à rotina da profissão.

Outros estudos relatam que os tratamentos que incluem uma visão integral do paciente e que envolvem técnicas de relaxamento corporal têm apresentado resultados positivos no que se refere à redução da intensidade e freqüência da dor e da ansiedade relacionada às limitações impostas pela doença. Técnicas consagradas e outras menos conhecidas pela comunidade incluem reeducação postural global (RPG); Do-In; exercícios de bioenergética; método de Feldenkvais; 
técnica de Jacobson; método de William; calatomia e biodança (PERNAMBUCO, 2001).

\subsection{Satisfação profissional}

O trabalho é elemento fundamental no desenvolvimento do ser humano, sendo também importante fonte de satisfação. Em vista deste fato, vários autores tentam definir o que vem a ser a satisfação profissional.

Segundo Pernambuco (2001) a satisfação com o trabalho poderia ser dividida em concreta e simbólica. A concreta estaria relacionada à proteção da vida, do bem estar físico, biológico e nervoso, ou seja, a saúde do corpo analisado em termos psicossomáticos. A simbólica trataria da vivência qualitativa da tarefa, significação do trabalho, necessidade dos desejos e motivações, dependendo do que a tarefa veicula do ponto de vista simbólico.

Outra definição é dada por Nicolielo e Bastos (2002), que relatam que a satisfação profissional atualmente vem sendo descrita como o estado emocional positivo resultante do prazer que se tem com as experiências do trabalho, estando fortemente associado a fatores como desempenho profissional, qualidade de vida, saúde física e mental e com a auto-estima do trabalhador.

Como a satisfação profissional influi diretamente na qualidade e em diversos setores da vida dos indivíduos, esta tem sido amplamente estudada em várias áreas profissionais, inclusive na Odontologia.

O trabalho odontológico envolve altos níveis de tensão e stress, cujas fontes estão associadas ao paciente, ao próprio profissional e, principalmente, à prática 
odontológica em si. Durante a prática profissional, o cirurgião-dentista pode se deparar com diversos fatores determinantes de tensão e stress como ter que lidar com o medo, ansiedade e nervosismo dos pacientes; o manejo de instrumentos cortantes, com risco para o profissional e paciente; a quebra de equipamentos; o isolamento do profissional no consultório; a ausência de pessoal auxiliar (auxiliar de consultório dentário e/ou técnico em higiene dental); o trabalho repetitivo; a carga de trabalho excessiva e às vezes até a competição entre profissionais.

Esses fatores debilitam o organismo, predispondo-o a contrair doenças, além de determinar a insatisfação e a fadiga mental que podem se manifestar como: irritabilidade; dificuldade de concentração e de relacionamento; lapsos de memória; perturbação da libido; insônia ou hipersônia; sentimento de culpa e de solidão; ansiedade e depressão (PERNAMBUCO, 2001).

Estudo realizado em Medunsa, África do Sul, por Harris e Zwane (2005), para traçar as expectativas e percepções com relação à satisfação na carreira com graduados do curso de odontologia, relata as expectativas do grupo pouco antes de se formarem, em 2003, na Faculdade de Odontologia de Medunsa, e as percepções observadas após o ano de Serviço Comunitário Compulsório, em 2004. Foi realizada análise de regressão nos dois grupos, sendo que as variáveis preditivas mais significantes para a satisfação geral do grupo de 2003 foram respeito (correlação positiva) e stress (correlação negativa).

Em estudo de Luzzi et al. (2005), diferenças na satisfação profissional entre profissionais do sexo feminino e masculino relacionaram-se à dimensão de tempo pessoal.

Outros aspectos das atividades exercidas podem influenciar na satisfação profissional. Em estudo realizado na Suécia, Pilgard et al. (2007) tinham por objetivo 
principal descrever o que empregados das clínicas de Cirurgia Buco-maxilo-facial do país entendiam por atividade de trabalho adequada. Os empregados dessas clínicas enfatizaram o trabalho livre, influente e intelectualmente estimulante, mas a discrepância entre o ideal e a realidade foi bem grande. Já, segundo estudo de Bengmark, Nilner e Rohlin (2007) na Suécia, verificou-se que a satisfação dos participantes com sua situação profissional estava correlacionada com a capacidade de exercer influência sobre sua situação de trabalho. Os autores concluíram que os participantes de sua pesquisa estavam satisfeitos com sua situação profissional.

Diferenças no nível de satisfação de profissionais que trabalham no setor público e no setor privado também são evidentes.

No estudo de Luzzi et al. (2005), realizado na Austrália, as diferenças nos níveis de satisfação entre dentistas dos setores privado e público relacionaram-se à autonomia, relacionamento com pacientes, dimensões de renda e recursos.

Quanto à prática, Pourat et al. (2007) realizaram um estudo transversal em clínicas particulares na Califórnia e destacaram que profissionais que atendiam pacientes com seguro da rede pública mostraram ter práticas diferentes daqueles que não atendiam, em termos de assistência ao paciente e estrutura da clínica.

Relacionando ainda o tipo de serviço em que o profissional trabalha e sua satisfação, Harris et al. (2008) observaram que dentistas generalistas (DG) do Sistema Nacional de Saúde (SNS) da Inglaterra, trabalhando integralmente neste Sistema, apresentaram menor probabilidade de estarem satisfeitos com seu trabalho, seguidos de dentistas do serviço particular do SNS e de dentistas trabalhando conjuntamente no SNS e em clínicas privadas. Dentistas particulares eram os mais satisfeitos, mas foram encontradas diferenças entre todos os grupos com relação à satisfação geral e a facetas de satisfação profissional relacionadas à 
restrição à capacidade de oferecer assistência de qualidade, ao controle do trabalho e ao desenvolvimento de habilidades técnicas.

Podemos também encontrar variação nos níveis de satisfação de acordo com a faixa etária dos cirurgiões-dentistas. Na pesquisa de Luzzi et al. (2005) diferenças de satisfação entre dentistas de diferentes grupos etários foram atribuídas a 6 dimensões: relacionamento com os colegas, relacionamento com pacientes, relacionamento com a equipe, tempo pessoal, responsabilidades coletivas e administrativas.

É notória a relação inversa entre satisfação profissional e stress e este fator tem sido destacado em muitos estudos. Confirmando essa informação, o estudo de Myers e Myers (2004), cujo objetivo foi investigar o stress geral, stress do trabalho e saúde de DG do Reino Unido, obteve como principal resultado a constatação de que o stress percebido foi significantemente correlacionado ao stress do trabalho em odontologia. Fatores estudados relacionados ao trabalho foram: a fragilidade da relação dentista-paciente, pressões relacionadas ao tempo e agenda/horário, problemas com a equipe e técnicos, insatisfação profissional, porcentagem de atendimento público (SNS) e número de horas trabalhadas por semana em conjunto, que explicaram aproximadamente metade do stress total dos dentistas em sua vida ( $p<0,0001)$. Comportamentos como o consumo de álcool também foram associados ao stress no trabalho $(p<0,001)$ e mais de um terço dos dentistas estavam acima do peso ou obesos. Cerca de $60 \%$ dos DG relataram estarem nervosos/ irritadiços, tensos ou deprimidos, 58,3\% relataram dor de cabeça, $60 \%$ dificuldade para dormir e $48,2 \%$ afirmaram que se sentem cansados sem razão aparente. Tudo isso foi relacionado ao stress no trabalho. Os níveis de sintomas psiquiátricos menores foram altos, com $32,0 \%$ de casos identificados. No geral esses achados indicam a 
natureza estressante da odontologia e dificuldades nas condições de trabalho. Sugerem que o próximo passo deveria ser o desenvolvimento de intervenções para ajudar os dentistas a reduzir o stress na prática odontológica.

Na mesma linha de pesquisa, Roth et al. (2003) tentaram descrever a relação entre stress ocupacional total, categorias de fatores estressores, satisfação profissional geral (SPG) e facetas de SPG em ortodontia. Os scores de stress ocupacional geral foram mais fortemente correlacionados à satisfação com o tempo pessoal $(p<0,01)$ e satisfação com gestão da clínica/consultório $(p<0,01)$. Fatores de stress relacionados ao trabalho $(p<0,01)$ e fatores estressores relacionados à renda $(p<0,01)$ foram as categorias com a maior correlação com a escala geral de satisfação profissional. Os ortodontistas participantes relataram baixo stress ocupacional e apresentaram scores de satisfação significantemente mais altos em todas as seções da Pesquisa de Satisfação de Dentistas, sendo que esta diferença foi maior na satisfação com tempo pessoal e gestão do consultório.

Neste campo do conhecimento, um conceito importante a ser conhecido é o burnout, considerado como a exaustão emocional, despersonalização e redução da realização pessoal. Altos níveis de burnout podem gerar efeitos deletérios em dentistas, sua família e pacientes.

$\mathrm{Na}$ pesquisa de Baran (2005), pouco menos que a metade dos dentistas estavam satisfeitos com sua profissão; 7,4\% haviam atingido níveis significantes de burnout e $83 \%$ percebiam a odontologia como sendo "muito estressante". Os tipos de personalidade sobrerepresentados em odontologia tenderam a um nível mais alto de satisfação e um nível mais baixo de burnout quando comparados ao grupo coorte. 
Outros fatores foram analisados em dentistas generalistas de Staffordshire, Wolverhampton e Dudley, Inglaterra e observou-se que dentistas com uma área de interesse especial tiveram scores mais altos em todas as categorias com exceção de qualidade de vida. A satisfação profissional geral foi mais alta entre cirurgiõesdentistas particulares e aqueles em clínicas de grupo e em locais urbanos. A correlação bi-variada mais alta ocorreu entre fornecimento de cuidado, renda, respeito e tempo profissional e, no geral, a satisfação profissional foi julgada como boa por esse grupo. O stress também foi o fator associado com a maior insatisfação. Esta pesquisa produziu resultados similares a estudos anteriores realizados nos Estados Unidos e sugere caminhos para melhorar a satisfação profissional (GILMOUR et al., 2005).

Em pesquisa realizada por Michel-Crosato, Koltiarenko e Biazevic (2006), $83,10 \%$ dos cirurgiões-dentistas estavam entre satisfeitos ou muito satisfeitos com a profissão.

Um avanço recente evidenciado pelas pesquisas neste campo é a mudança do oposto conceitual de burnout: o envolvimento no trabalho. Te Brake et al. (2007) realizaram um estudo para esclarecer esses conceitos e determinar seus níveis entre os dentistas. Encontrou-se relação inversa entre envolvimento e burnout. O estudo observou que os níveis gerais de burnout entre dentistas generalistas holandeses são baixos e os níveis de envolvimento indicam que esses profissionais têm uma atitude positiva em relação ao trabalho.

Gorter et al. (2008), sugerem que para prevenir o burnout seria recomendável um aumento da consciência dos dentistas para a importância de ter tempo e espaço suficientes para o desenvolvimento de aspectos estimulantes do trabalho. 
Os recursos disponíveis também podem estar relacionados ao envolvimento dos profissionais com seu trabalho, influenciando diretamente sua satisfação. Hakanen, Bakker e Demerouti (2005) realizaram estudo que teve como foco as demandas e recursos de trabalho, além do envolvimento profissional, entre 1.919 dentistas funcionários do setor público da Finlândia. Baseado no modelo Demanda Recursos de Trabalho, foi suposto que a relação inversa entre as demandas (carga de trabalho, ambiente físico) e o envolvimento profissional poderia ser mais fraca quando dentistas têm muitos recursos (variedade de habilidades profissionais requeridas, contatos com colegas). Baseando-se na Teoria de Conservação de Recursos, também foi criada a hipótese de que recursos de trabalho são fatores importantes para manter o envolvimento sob condições de grande demanda de trabalho. A conclusão principal foi que os recursos de trabalho são instrumentos úteis para auxiliar os profissionais a lidarem com grandes demandas em odontologia e colaboram para que se mantenham engajados.

Gorter et al. (2006), em pesquisa realizada na Alemanha, realizaram um estudo sobre recursos de trabalho na prática odontológica daquele país. O objetivo da pesquisa era desenvolver um instrumento que medisse os recursos de trabalho entre dentistas, avaliasse a importância relativa desses recursos e os relacionasse à satisfação profissional. Confirmando outras pesquisas, todos os recursos de trabalho mostraram correlação positiva com a satisfação profissional. A discussão do estudo sugere que o incentivo a uma maior consciência a respeito dos recursos de trabalho seria fundamental para a prevenção do burnout neste grupo de profissionais.

Estudo posterior do mesmo autor (GORTER et al., 2008) teve como objetivo determinar o nível de envolvimento entre dentistas e investigar quais recursos de trabalho odontológico se correlacionavam positivamente com o envolvimento. Os 
autores concluíram que os dentistas mostraram médias relativamente elevadas em uma mensuração de envolvimento quando comparados a outras profissões e os recursos de trabalho mais valorizados foram "Resultados imediatos/ Estéticos"; os recursos "Idealismo/Orgulho" e "Cuidado com o paciente", e mostraram maior valor preditivo com relação ao envolvimento entre os dentistas.

Além dos recursos, há também a influência dos fatores ambientais na satisfação desses profissionais. Trabalho realizado na Coréia do Sul por Jeong et al. (2006), investigou o nível e a distribuição da satisfação profissional e explorou fatores ambientais do trabalho associados à satisfação profissional dos dentistas coreanos, encontrando uma média de satisfação profissional geral de 3,2 em 5 pontos. Em termos de fatores do ambiente de trabalho, o aspecto mais satisfatório foi o relacionamento com os pacientes $(3,7)$ e o menos satisfatório foi o tempo pessoal $(2,8)$. O estudo sugere que o relacionamento com pacientes, a percepção de renda, o tempo pessoal, a equipe e o treinamento especializado são fatores importantes do ambiente de trabalho para a satisfação profissional entre os dentistas coreanos.

Pesquisando o mesmo tema, Puriene et al. (2007) avaliaram, através de questionário, o nível de satisfação profissional entre dentistas lituanos, pesquisando a satisfação com diferentes fatores ambientais do trabalho e relacionando-os à satisfação profissional global. As áreas de trabalho menos satisfatórias foram seguro social e renda; as de maior satisfação foram as de relacionamento com pacientes e com outros profissionais. No geral, observou-se que os dentistas lituanos vivenciam grande satisfação profissional e os estudos de pós-graduação, associados à possibilidade ilimitada de desenvolvimento profissional, têm impacto mais positivo para a satisfação profissional do que os fatores ambientais. 
O nível de satisfação profissional também pode influenciar na retenção de cirurgiões-dentistas em empregos. Bolin e Shulman (2005) conduziram um estudo para identificar fontes de insatisfação que afetam a permanência de dentistas que estão começando a trabalhar nas clínicas de centros de saúde comunitária nos Estados Unidos e para determinar o salário atual destes profissionais. Dentistas de todo o país foram pesquisados a respeito de seus salários e indicadores de satisfação no trabalho e os autores analisaram associações entre os indicadores de satisfação profissional, salários e intenções dos dentistas de deixar de trabalhar nos centros. Os resultados mostram que profissionais do setor privado formavam o maior grupo de dentistas recrutado pelos centros (54,5\%), porém, 31,2\% dos dentistas empregados naquela época não pretendiam permanecer nas clínicas odontológicas desses centros. O salário não estava significantemente associado com a intenção de deixar o emprego; os anos de experiência, a liberdade de decisão profissional, a motivação altruísta, a importância dada a pagamento de empréstimo e a quantidade de tempo permitido para administração foram significantemente associados com intenções de mudança na carreira. 


\section{PROPOSIÇÃO}

O presente estudo teve por objetivo verificar o perfil da força de trabalho de um grupo de profissionais representado pelos cirurgiões-dentistas que desenvolviam suas atividades em uma empresa do setor privado do Estado de São Paulo no ano de 2008, verificando aspectos relativos às características sociodemográficas, ao perfil das atividades profissionais desenvolvidas, à educação continuada, às possíveis queixas de saúde e à satisfação profissional do grupo estudado. 


\section{MATERIAL E MÉTODOS}

\subsection{Tipo de estudo}

Estudo observacional, transversal, tipo inquérito, descritivo.

\subsection{População do estudo}

Todos os cirurgiões-dentistas que exerciam suas atividades nas unidades da empresa no Estado de São Paulo: cerca de 230 profissionais, excetuando-se algumas poucas vagas em aberto.

\subsection{Local de estudo}

A empresa dentro da qual foi realizado o presente estudo se baseia no conceito de serviço social custeado pelo empresariado, é de caráter privado e voltada ao bem-estar social, tendo como um de seus princípios basilares a promoção da saúde e abrangendo o desenvolvimento de atividades na área de saúde, lazer, atividades esportivas e cultura. Seu objetivo é a promoção do bem 
estar social, a melhoria da qualidade de vida e o desenvolvimento cultural dos trabalhadores de determinada categoria que podem ser associados e seus dependentes, bem como da comunidade em geral.

A pesquisa foi desenvolvida com os cirurgiões-dentistas que estavam trabalhando nas 23 clínicas odontológicas (10 na Grande São Paulo e 13 em cidades do interior do Estado) existentes em unidades operacionais da empresa no Estado de São Paulo, no ano de 2008.

\subsection{Critérios de inclusão}

Cirurgiões-dentistas do quadro da empresa, com o termo de consentimento esclarecido assinado.

\subsection{Critérios de exclusão}

Profissionais afastados: em férias; licença (médica, gala, maternidade ou nojo); em serviço externo; compensando horas e os que preferiram não preencher o questionário. 


\subsection{Instrumento de coleta de dados}

A coleta de informações foi realizada por meio da utilização de um questionário de perguntas fechadas e abertas, agrupadas por assuntos (Apêndice B).

O questionário apresenta 5 agrupamentos. Inicialmente há perguntas para caracterização da amostra, relativas ao gênero, idade e região de residência.

A formação profissional é abordada no segundo bloco, que apresenta questionamentos como qual o tipo e o nome da instituição em que cursou a graduação, quantos anos tem de formado, se possui título de especialista, mestrado e/ou doutorado e em quais áreas e se possui pós-doutorado; se participou de congresso científico nos últimos dois anos, se tem acesso a revistas científicas e se é membro de alguma sociedade científica.

A terceira parte destaca o mercado de trabalho e a atuação profissional, com temas como situação profissional, atuação em serviço privado e público, atendimento de convênios, atividade docente, remuneração média mensal, tempo de dedicação (horas/semana), posição de trabalho e problemas de saúde no último ano.

O quarto agrupamento, com perguntas direcionadas apenas às cirurgiãsdentistas, se refere à participação da mulher na odontologia, questionando sobre a valorização em relação ao homem, a discriminação e as dificuldades encontradas no exercício profissional.

O último bloco é composto por uma escala de satisfação profissional. 


\subsection{Escala de satisfação}

A escala de satisfação utilizada neste estudo foi a elaborada e testada por Michel-Crosato (2008), a partir do modelo proposto por Jeong et al. (2006). O instrumento apresenta 29 perguntas, distribuídas em 7 blocos (Quadro 4.1).

Para conseguir o escore de satisfação de cada bloco principal calculou-se a média aritmética dos itens de cada bloco. As perguntas de números $1,6,8,9,10,11,13,16,20,23,26$ e 29 tiveram seu escore invertido $(5=1,4=2,3=3,2=4,1=5)$, em função das características próprias do instrumento.

\begin{tabular}{|l|l|}
\hline Blocos & Perguntas \\
\hline Satisfação geral com o trabalho & $5,6,9,12,14,17,20$ \\
\hline Percepção de renda & $2,10,21,23,25$ \\
\hline Tempo pessoal & $7,15,29$ \\
\hline Tempo profissional & $1,4,22,26$ \\
\hline Equipe & $8,18,19$ \\
\hline Relacionamento com pacientes & $11,16,24,27$ \\
\hline Fornecimento de assistência/atendimento & $3,13,28$ \\
\hline
\end{tabular}

Quadro 4.1 Blocos de agrupamento da escala de satisfação 


\subsection{Método de aplicação do questionário}

Para obter as informações constantes da proposição deste estudo, foi utilizado um questionário com perguntas agrupadas por assuntos.

$\mathrm{Na}$ fase de planejamento foram fornecidos à pesquisadora, pela coordenação estadual de odontologia da empresa, dados sobre a quantidade de cirurgiõesdentistas por clínica (dentre as Unidades Operacionais do Estado de São Paulo que contêm o serviço) e conferidos os nomes dos dentistas coordenadores de cada clínica. No total são 23 clínicas, que variam na quantidade de períodos de funcionamento (matutino/vespertino/noturno), quantidade de equipamentos e, consequentemente, no número de profissionais alocados.

Os questionários foram enviados pela pesquisadora através de malote (serviço de correspondência interna) aos dentistas coordenadores, que haviam sido previamente contatados por e-mail (elaborado em conjunto com a pesquisadora) enviado pela coordenação estadual de odontologia, com informações sobre a pesquisa e orientações de como deveriam ser entregues e recolhidos os envelopes contendo a pesquisa (cada envelope continha um questionário e um termo de consentimento esclarecido). Os coordenadores seriam os intermediários: entregariam um envelope por cirurgião-dentista; os envelopes deveriam ser recolhidos posteriormente e enviados de volta para a pesquisadora, por malote, em duas semanas.

Foram utilizados papéis timbrados. A utilização de papéis timbrados objetivou aumentar as possibilidades de resposta, fornecendo credibilidade à pesquisa e 
diminuindo intercorrências como desconfiança, temor de invasão de privacidade e outras (OPPENHEIM, 1993).

\subsection{Digitação e análise dos dados}

Os dados foram digitados e analisados no programa STATA 10.0. Realizouse distribuição de freqüências e medidas de tendência central e de dispersão, e também foram indicados os valores mínimos e máximos. A regressão binomial negativa foi o teste utilizado para testar a associação com as variáveis associadas. O nível de significância considerado foi de 5\% em todos os testes realizados.

\subsection{Considerações éticas}

A pesquisa foi encaminhada aos cirurgiões-dentistas com uma carta explicativa para esclarecê-los sobre o propósito do estudo. Para que fosse obtida a autorização para a realização do estudo, procedeu-se ao preenchimento em duas vias do termo de consentimento livre e esclarecido (Apêndice A), como preconiza a Resolução 196 do Conselho Nacional de Ética em Pesquisa (CONEP). O projeto de pesquisa foi encaminhado e aprovado pelo Comitê de Ética em Pesquisa da FOUSP (Anexo A) e também obteve aprovação da direção da empresa no Estado de São Paulo. 


\section{RESULTADOS}

\subsection{Distribuição sociodemográfica}

O estudo contou com a participação de 194 cirurgiões-dentistas (taxa de resposta $=88,58 \%$, visto que 219 receberam, efetivamente, o questionário) que exerciam atividades profissionais em uma empresa de caráter privado, no final de 2008. Em relação às características sócio-demográficas dos participantes, 68,04\% $(\mathrm{N}=132)$ eram do gênero feminino e 31,96\% $(\mathrm{N}=62)$ do gênero masculino. Na cidade de São Paulo, a região que continha o maior número de profissionais foi a zona sul, com $26,29 \%$ do total. Observa-se que $43,30 \%$ dos cirurgiões-dentistas residem em outros municípios (Tabela 5.1). 
Tabela 5.1- Distribuição dos Cirurgiões-Dentistas segundo gênero e região de residência. São Paulo, 2008

\begin{tabular}{lcc}
\hline Variáveis & $n$ & $\%$ \\
\hline Gênero & 132 & 68,04 \\
Feminino & 62 & 31,96 \\
Masculino & & \\
Região de Residência & 10 & 5,15 \\
Norte & 51 & 26,29 \\
Sul & & 6,70 \\
Leste & 13 & 12,89 \\
Oeste & 25 & 2,06 \\
Centro & & 43,30 \\
Outros municípios & 4 & \\
\hline 7 profissionais ño responderam & & \\
\hline
\end{tabular}

*7 profissionais não responderam a essa questão 
Os profissionais estudados apresentavam idade entre 25 e 54 anos (média de 35,78 anos) e o tempo médio de formado foi de 12,85 anos, sendo o mínimo 3 anos e o máximo 32 anos, como mostra a tabela 5.2 .

Tabela 5.2- Distribuição dos Cirurgiões-Dentistas segundo idade e anos de formados. São Paulo, 2008

\begin{tabular}{lccc}
\hline Variáveis & Média & Desvio- & Mín/Máx \\
& & Padrão (DP) & \\
\hline Idade & 35,78 & 6,08 & $25,00 / 54,00$ \\
Anos de formado & 12,85 & 5,91 & $3,00 / 32,00$ \\
\hline
\end{tabular}

\subsection{Educação continuada}

Quanto à formação, 64,43\% estudaram em faculdades públicas e 35,57\% em faculdades particulares; 116(59,79\%) haviam concluído curso de especialização, 26 $(13,40 \%)$ mestrado e $10(5,15 \%)$ doutorado (Tabela 5.3). Alguns profissionais fizeram anotações no questionário sobre cursos de especialização ou pósgraduação em andamento, mas este fator não foi avaliado. 
Tabela 5.3- Distribuição dos Cirurgiões-Dentistas segundo tipo de faculdade e cursos de educação continuada realizados. São Paulo, 2008

\begin{tabular}{lll}
\hline Variáveis & $n$ & $\%$
\end{tabular}

Estudou em Faculdade:

Particular

125

35,57

Pública

69

64,43

Concluiu curso de especialização:

Sim

Não

78

40,21

Concluiu curso de mestrado:

Sim

26

13,40

Não

168

86,60

Concluiu curso de doutorado:

Sim

Não

184

94,85

Considerando-se a especialização, foi realizada uma divisão dos profissionais segundo curso de especialização em área básica, clínica ou social (Tabela 5.4). Muitos profissionais cursaram várias especialidades (até 3), às vezes todas da mesma área (endodontia, cirurgia e periodontia, por exemplo, todas clínicas), mas esta descrição não está detalhada neste estudo. 
Tabela 5.4- Distribuição dos Cirurgiões-Dentistas segundo especialização em área básica, clínica ou social. São Paulo, 2008

\begin{tabular}{lll}
\hline Variáveis & $n$ & $\%$
\end{tabular}

Especialização área básica:

Sim

7

3,61

Não

187

96,39

Especialização área clínica:

Sim

93

47,94

Não

101

52,06

Especialização área social:

Sim

25

12,89

Não

169

87,11 
Com relação ao acesso a atualizações e produções científicas, $79,38 \%$ relatam ter participado de congresso científico nos últimos dois anos, 87,63\% têm acesso a revistas científicas e $30,41 \%$ são membros de alguma sociedade científica (Tabela 5.5).

Tabela 5.5- Distribuição dos Cirurgiões-Dentistas considerando-se o acesso a atualizações e produções científicas. São Paulo, 2008

\begin{tabular}{lcc}
\hline Variáveis & $\boldsymbol{n}$ & $\%$ \\
\hline Participou de congresso científico nos & & \\
últimos dois anos: & 154 & 79,38 \\
$\quad$ Sim & 40 & 20,62 \\
Não & & \\
Acesso a revistas científicas: & 170 & 87,63 \\
Sim & 24 & 12,37 \\
Não & & 30,41 \\
É membro de alguma sociedade científica: & 59 & 69,59 \\
Sim & 135 & \\
Não & & \\
\hline
\end{tabular}




\subsection{Atuação profissional}

A grande maioria trabalha em consultório ou clínica particular $(78,35 \%)$ sendo que, entre estes, 32,99\% atendem convênios. Com relação a outras atividades profissionais, 30,93\% ( $\mathrm{N}=60)$ atuam também no serviço público e $7,22 \%(\mathrm{~N}=14)$ exercem atividade docente (Tabela 5.6).

Tabela 5.6- Distribuição dos Cirurgiões-Dentistas segundo outras atividades exercidas em odontologia. São Paulo, 2008

\begin{tabular}{lll}
\hline Variáveis & $n$
\end{tabular}

Trabalha em consultório particular:

$\operatorname{Sim}$

152

78,35

Não

42

21,65

Atende convênio:

Sim

64

32,99

Não

130

67,01

Trabalha em serviço público:

Sim

60

30,93

Não

134

69,07

Exerce atividade docente:

Sim

Não 
A média de horas trabalhadas por semana foi de 41,08 (mínimo 8 a máximo 96) horas e a quantidade de pacientes atendidos por turno variou de 3 a 18 (Tabela 5.7).

Tabela 5.7- Distribuição dos Cirurgiões-Dentistas segundo horas trabalhadas por semana, posição de trabalho e pacientes por turno. São Paulo, 2008

\begin{tabular}{lccc}
\hline Variáveis & Média & Desvio- & Mín/Máx \\
& & Padrão & \\
\hline Horas trabalhadas/semana & 41,08 & 14,56 & $8,00 / 96,00$ \\
Pacientes por turno & 6,05 & 1,97 & $3,00 / 18,00$ \\
\hline
\end{tabular}

Observa-se que 50\% do total preferem a posição de 9h e a segunda posição mais utilizada $(38,02 \%)$ foi $11 \mathrm{~h}$ (Tabela 5.8$)$.

Tabela 5.8- Distribuição dos Cirurgiões-Dentistas segundo posição de trabalho. São Paulo. 2008

\begin{tabular}{ccc}
\hline Variáveis & $\boldsymbol{n}$ & $\%$ \\
\hline 1 & 4 & 2,08 \\
3 & 3 & 1,56 \\
9 & 96 & 50,00 \\
10 & 9 & 4,69 \\
11 & 73 & 38,02 \\
12 & 7 & 3,65 \\
\hline
\end{tabular}

* 2 profissionais não responderam à essa questão. 


\subsection{Risco ocupacional}

Apenas 54 profissionais $(27,84 \%)$ não apresentaram nenhum problema (dor, desconforto ou dormência) nos braços, mãos, costas ou ombros nos últimos 12 meses. As porcentagens de incômodos relatados foram as seguintes: braços 17,01\%, mãos - 26,29\%, costas - 57,22\% e ombros - 33,51\% (Tabelas 5.9 e 5.10).

Tabela 5.9- Distribuição dos Cirurgiões-Dentistas segundo terem tido algum problema como dor, desconforto ou dormência nos últimos 12 meses em braços, mãos, costas e/ou ombros. São Paulo, 2008

\section{Variáveis}

$n$

$\%$

Alguma dor, desconforto ou dormência nos

últimos 12 meses:

Sim

140

72,16

Não

54

27,84

Braços:

Sim

Não

Mãos:

Sim

51

26,29

Não

143

73,71

Costas:

Sim

Não

83

42,78

Ombro:

Sim

65

33,51

Não 
Tabela 5.10- Distribuição dos Cirurgiões-Dentistas de acordo com a quantidade de dores, desconforto ou dormência relatados. São Paulo, 2008

\begin{tabular}{lccc}
\hline Variáveis & Média & Desvio- & Mín/Máx \\
& & Padrão & \\
\hline Quantas dores, & & & \\
desconforto e/ou & 1.340206 & 1.237469 & $0,00 / 4,00$ \\
dormência: & & & \\
\hline
\end{tabular}

Questionados quanto à valorização de práticas saudáveis, 188 (96,91\%) responderam que valorizam essas práticas no dia-a-dia (Tabela 5.11).

Tabela 5.11- Distribuição dos Cirurgiões-Dentistas considerando-se práticas saudáveis. São Paulo, 2008

\begin{tabular}{lcc}
\hline Variáveis & $\boldsymbol{n}$ & $\%$ \\
\hline Valoriza práticas saudáveis no dia-a-dia: & & \\
Sim & 188 & 96,91 \\
Não & 6 & 3,09 \\
\hline
\end{tabular}




\subsection{Gestão em odontologia}

Observa-se que os profissionais deste grupo acreditam que a gestão em odontologia é importante: 96,91\% acham importante o conhecimento de processos administrativos para a gestão profissional de equipes, 68,04\% gostam de ser mediadores, transmitindo e discutindo informações entre diferentes níveis hierárquicos e $80,93 \%$ tem interesse em adquirir conhecimentos sobre como gerir pessoas (Tabela 5.12).

Tabela 5.12- Distribuição dos Cirurgiões-Dentistas sobre aspectos relativos à gestão em odontologia. São Paulo, 2008

\begin{tabular}{lll}
\hline Variáveis & $n$ & $\%$
\end{tabular}

Acha importante o conhecimento de

processos administrativos para a gestão

profissional de equipes:

$\operatorname{Sim}$

Não

Gosta de ser mediador, transmitindo e

discutindo informações entre diferentes

níveis hierárquicos:

Sim

Não

Tem interesse em adquirir conhecimentos

sobre como gerir pessoas (gestão de RH):

Sim

80,93

Não
188

96,91

5

2,58
37

19,07

Não 


\subsection{Participação da mulher na odontologia}

O questionário apresentava, na sequência, questões a serem respondidas apenas pelas profissionais do sexo feminino participantes do estudo $(\mathrm{N}=132)$. As cirurgiãs-dentistas responderam perguntas relativas à sua percepção quanto à valorização da mulher e se achavam que sofriam discriminação por serem profissionais do sexo feminino. A grande maioria respondeu que é tratada da mesma maneira (72,73\%) e que não sofre discriminação $(90,15 \%)$ (Tabela 5.13).

Tabela 5.13- Distribuição das Cirurgiãs-Dentistas segundo aspectos relativos a participação da mulher na odontologia. São Paulo, 2008

\begin{tabular}{lcc}
\hline Variáveis & $\boldsymbol{n}$ & $\%$ \\
\hline Acredita que a mulher em relação ao & & \\
homem no exercício profissional: & 7 & 5,30 \\
É mais valorizada & 96 & 72,73 \\
É tratada da mesma maneira & 29 & 21,97 \\
É menos valorizada & & \\
"Você, como profissional, sofre & & 9,85 \\
discriminação?": & 13 & 90,15 \\
$\quad$ Sim & 119 & \\
$\quad$ Não & & \\
\hline
\end{tabular}




\subsection{Satisfação profissional}

O nível de satisfação dos participantes alcançou um valor de 3,45, considerando-se uma escala de 1 a 5 . Os valores de cada bloco verificados foram, respectivamente, os seguintes: satisfação geral com o trabalho/emprego: média=3,39 e $\mathrm{DP}=0,89$; percepção de renda: média=3,21 e $\mathrm{DP}=0,74$; tempo pessoal: 2,60 e $\mathrm{DP}=1,06$; tempo profissional: média=3,13 e $\mathrm{DP}=0,71$; equipe: média=3,35 e DP=0,98; relacionamento com pacientes: média=4,34 e DP=0,59 e fornecimento de assistência/atendimento: média=4,16 e DP=0,58 (Tabela 5.14).

Tabela 5.14- Distribuição dos Cirurgiões-Dentistas segundo satisfação no trabalho. São Paulo, 2008

\begin{tabular}{lccc}
\hline Blocos & Média & Desvio- & Mín/Máx \\
& & Padrão & \\
\hline Satisfação geral com o & 3,39 & 0,89 & $1,14 / 5,00$ \\
trabalho & 3,21 & 0,74 & $1,2 / 5,00$ \\
Percepção de renda & 2,60 & 1,06 & $1,00 / 5,00$ \\
Tempo pessoal & 3,13 & 0,71 & $1,00 / 5,00$ \\
Tempo profissional & 3,35 & 0,98 & $1,00 / 5,00$ \\
Equipe & & & $1,75 / 5,00$ \\
Relacionamento com & 4,34 & 0,59 & $2,66 / 5,00$ \\
pacientes & & & \\
Fornecimento de & 4,16 & 0,58 & $2,24 / 4,72$ \\
assistência/atendimento & & & \\
\hline Todos os blocos & 3,45 & & \\
\hline
\end{tabular}


Analisando os dados da tabela 5.15 podemos perceber que as variáveis horas trabalhadas, dor e relacionamento com pacientes estão associadas ao gênero.

Tabela 5.15- Relação entre gênero e fatores associados. São Paulo, 2008

\begin{tabular}{lccc}
\hline Variável & $\boldsymbol{R P}$ & $\boldsymbol{P}$ & IC (95\%) \\
\hline Horas trabalhadas & 1,23 & $0,000^{*}$ & $1,11-1,36$ \\
Pacientes por turno & 1,06 & 0,218 & $0,96-1,17$ \\
Especialidade & 1,01 & 0,881 & $0,91-1,12$ \\
Dor & 0,70 & $0,004^{*}$ & $0,55-0,89$ \\
Satisfação total & 0,99 & 0,629 & $0,95-1,03$ \\
Bloco 6 (Relacionamento & & & $0,89-0,99$ \\
com pacientes) & 0,94 & $0,013^{*}$ & \\
\hline
\end{tabular}


Quanto às horas trabalhadas, houve diferença estatisticamente significante quando relacionada às variáveis: gênero $(p=0,000)$, consultório particular $(p=0,002)$, serviço público $(0,000)$, percepção de renda $(0,019)$ e tempo pessoal $(p=0,000)$ (Tabela 5.16).

Tabela 5.16- Relação entre horas trabalhadas e fatores associados. São Paulo, 2008

\begin{tabular}{lccc}
\hline Variável & $\boldsymbol{R P}$ & $\boldsymbol{P}$ & $\boldsymbol{I C}$ (95\%) \\
\hline Gênero masculino & 1,23 & $0,000^{\star}$ & $1,11-1,36$ \\
Idade & 1,00 & 0,567 & $0,99-1,00$ \\
Tempo de formado & 1,00 & 0,391 & $0,99-1,00$ \\
Especialização & 0,97 & 0,560 & $0,87-1,07$ \\
Consultório particular & 1,25 & $0,002^{*}$ & $1,09-1,44$ \\
Serviço público & 1,24 & $0,000^{*}$ & $1,12-1,37$ \\
Bloco 2 (Percepção de & & & $1,01-1,15$ \\
renda) & 1,08 & $0,019^{*}$ & \\
Bloco 3 (Tempo pessoal) & 0,87 & $0,000^{*}$ & $0,83-0,91$ \\
Satisfação total & 0,95 & 0,052 & $0,85-1,06$ \\
\hline
\end{tabular}




\section{DISCUSSÃO}

Tendo em vista o maior conhecimento da realidade dos cirurgiões-dentistas em nosso país, é fundamental verificar se as alterações que a Odontologia vem sofrendo estão modificando o exercício profissional, o perfil dos profissionais, o tipo de serviço oferecido, o número de horas trabalhadas, os estudos de pós-graduação e o nível de satisfação profissional, a fim de avaliar a força de trabalho que milita na área.

O presente estudo contou com a participação de 194 cirurgiões-dentistas (taxa de resposta $=88,58 \%$ ) que exerciam atividades profissionais em uma empresa de caráter privado, no final de 2008. Analisando informações sobre características sociodemográficas dos participantes, observamos que 68,04\% ( $N=132)$ eram do gênero feminino e 31,96\% $(N=62)$ do gênero masculino. A maior porcentagem de mulheres está de acordo com a tendência à feminilização da odontologia, descrita por Costa, Durães e Abreu (2009), Moimaz (2003) e Moimaz, Saliba e Blanco (2003) e também encontrada em vários outros estudos (BENGMARK; NILNER; ROHLIN, 2007; HJALMERS, 2006; MCEWEN; SEWARD, 1988; MICHEL-CROSATO et al., 2003; MICHEL-CROSATO; KOLTIARENKO; BIAZEVIC, 2006; PARAJARA, 2000; PERRI DE CARVALHO, 1995a,b; SERPA, 1991).

Na cidade de São Paulo, a região com o maior número de profissionais foi a zona sul, com $26,29 \%$ do total, seguida da zona oeste 12,89 . Na zona leste residiam $6,70 \%$ dos cirurgiões-dentistas da pesquisa, na zona norte 5,15\% e 2,06\% na região central. Além destes, 43,30\% (84 profissionais) afirmaram residir em outras cidades, o que já era esperado, pois foram enviados questionários aos profissionais que trabalham nas clínicas em unidades da empresa localizadas em 14 cidades além do 
município de São Paulo (como citado nos materiais e métodos, foram convidados a participar da pesquisa os cirurgiões-dentistas de todas as clínicas da empresa do Estado de São Paulo). A porcentagem de não resposta a este item foi de 3,61\% $(\mathrm{N}=7)$.

Os cirurgiões-dentistas estudados apresentavam idade entre 25 e 54 anos (média de 35,78 anos) se aproximando dos achados de Jeong et al. (2006) onde 20,2\% tinham até 35 anos, 56,2\% entre 36 e 45 anos e 16,1\% entre 46 e 55 anos e com valores superiores aos encontrados por Bengmark, Nilner, Rohlin (2007), onde a média foi de 26 anos. Regis Filho, Michels e Sell (2006) observaram uma concentração de profissionais entre 30 a 39 anos e entre 40 a 49 anos com 41,70\% e $27,50 \%$, respectivamente, ou seja, nas faixas etárias de maior produtividade dos cirurgiões-dentistas.

A variável tempo de formado apresentou grande extensão, evidenciando-se que a empresa contrata pessoas com poucos anos de formado ( 3 anos) ou mais, e também fica evidente que há profissionais que iniciaram mais jovens e trabalham há muitos anos na empresa. O tempo médio de formado foi de 12,85 anos. Os entrevistados no estudo de Santos e Peloggia (2002) estavam distribuídos em: até cinco anos de formatura $-35 \%$, de seis a dez anos $-24 \%$, de onze a vinte anos $27 \%$ e mais de vinte anos $-14 \%$.

Muitas são as atividades que os cirurgiões-dentistas desenvolvem em sua atuação profissional.

Além de todos os cirurgiões-dentistas entrevistados trabalharem no setor privado, $78,35 \%$ trabalham em consultório ou clínica particular (índice alto, semelhante ao encontrado por CÓRDON, 1991) sendo que, entre estes, 32,99\% atendem convênios. As mesmas tendências foram evidenciadas em Bastos et al. 
(2003) onde grande parte dos profissionais trabalhavam em consultório particular próprio (38,8\%) ou por porcentagem (25,5\%) e 26,5\% atendiam algum convênio ou cooperativa. Porcentagens mais altas de profissionais atendendo convênios foram apresentadas por DÁvila et al. (2007) - 61,7\% e em estudo de 2003 realizado pelo INBRAPE, que afirmou que $47,6 \%$ dos cirurgiões-dentistas da amostra nacional atendiam convênios.

Com relação a outras atividades profissionais, 30,93\% atuam também no serviço público (dado que pode estar relacionado ao grande número de horas dedicadas por semana) quantidade maior quando comparada a Bastos et al. (2003) onde 12,2\% trabalhavam na rede pública e a Moimaz (2003), em que é relatado que, apesar de 2,4\% atuarem somente no serviço público, 21\% atuavam no serviço público e também em outra modalidade. Outra observação importante do estudo é que $7,22 \%$ dos dentistas exercem atividade docente, dado coerente considerandose a porcentagem de profissionais que tem o título de mestre e/ou doutor $(18,55 \%)$.

Quanto à carga horária, a média de horas trabalhadas por semana foi de 41,08 (mínimo 8 a máximo 96 horas), seguindo a mesma tendência demonstrada nos estudos de Moimaz (2003) onde $47,23 \%$ dos cirurgiões-dentistas relataram praticar uma jornada de trabalho de mais de 40 horas semanais e Jeong et al. (2006), em que $83,4 \%$ dos participantes também trabalhavam mais que 40 horas semanais (66,8\% entre 41 e 51 horas e $16,6 \%$ mais que 51 horas).

Analisando-se as respostas sobre a posição de trabalho, verifica-se que 50\% do total preferem a posição de $9 \mathrm{~h}$ e a segunda posição mais utilizada $(38,02 \%)$ foi 11h; em posições semelhantes, 4,69\% marcaram 10h e 3,65\%, 12h, dados próximos aos achados de Michel-Crosato, Koltiarenko e Biazevic (2006) onde as localizações 
que correspondem a 9,10,11 e $12 \mathrm{~h}$ foram as preferidas por cerca de $56,86 \%$ dos profissionais.

Buscando uma melhor adequação para trabalho, seguem-se 2,08\% de profissionais, provavelmente canhotos, que preferem a posição $1 \mathrm{~h}$ e 1,56\% a posição 3h.

No levantamento foram também compiladas informações referentes ao tipo de instituição de ensino onde os profissionais concluíram a graduação e aos cursos de educação continuada realizados.

Quanto à formação, 64,43\% estudaram em faculdades públicas e 35,57\% em faculdades particulares, divergindo da pesquisa realizada com amostra nacional onde $52,1 \%$ dos participantes formaram-se em faculdades particulares (INSTITUTO BRASILEIRO DE ESTUDOS E PESQUISAS SOCIOECONÔMICAS, 2003). Este fator pode refletir o adequado processo seletivo aplicado pela empresa para contratação dos profissionais, visto que, geralmente, as faculdades públicas oferecem cursos de maior rigor e qualidade quando comparados aos oferecidos por algumas faculdades particulares, que por vezes valorizam o lucro em detrimento de recursos para uma melhor aprendizagem e preparo de seus alunos.

Sobre a educação continuada, 59,79\% haviam concluído curso de especialização, valor superior ao encontrado por Bastos et al. (2003) em que 52,3\% haviam feito ou estavam fazendo aperfeiçoamento/especialização, Moimaz (2003), 41\%, Jeong et al. (2006), 35,5\% e D'Ávila et al. (2007), onde apenas 53,3\% haviam concluído curso de especialização. O elevado índice de especialistas pode estar relacionado às oportunidades de bolsa de estudos oferecida pela empresa aos cirurgiões-dentistas contratados. 
Podemos ainda verificar que no presente estudo a grande maioria dos especialistas cursaram disciplinas clínicas $(47,94 \%)$, o que condiz com o grande número de horas dedicadas à pratica profissional e ao atendimento de pacientes na empresa, no consultório particular e/ou no serviço púbico.

Quanto ao mestrado e doutorado, o presente estudo apresentou valores inferiores: $13,40 \%$ mestrado e 5,15\% doutorado, enquanto Bastos et al. (2003) observou $47,7 \%$ de participantes que haviam concluído o mestrado e 7,7\% doutorado e Jeong et al. (2006), 17,7\% mestrado e 29,6\% doutorado.

Com relação ao acesso a atualizações e produções científicas, $79,38 \%$ relatam ter participado de congresso científico nos últimos dois anos, 87,63\% têm acesso a revistas científicas e 30,41\% são membros de alguma sociedade científica, valores muito próximos aos levantados em pesquisa nacional pelo Instituto Brasileiro de Estudos e Pesquisas Socioeconômicas (2003), onde 76,4\% dos cirurgiõesdentistas afirmaram ter participado de congresso nos últimos 2 anos e 81,3\% relataram ler publicações científicas e de Michel-Crosato (2008), que obteve as seguintes porcentagens: $83,14 \%$ dos participantes participaram de congresso no ano anterior, $79,83 \%$ faziam leitura de revistas científicas e $21,49 \%$ participavam de sociedade odontológica. Esses achados reafirmam que os cirurgiões-dentistas procuram manter-se informados e atualizados, acompanhando os avanços científicos e tecnológicos de sua área de atuação.

A Odontologia é considerada uma profissão estressante, sendo freqüentemente associada a agravos à saúde, tanto de ordem física como psíquica. $\mathrm{Na}$ análise de complicações e riscos ocupacionais, a postura de trabalho é um fator preocupante, pois dela podem derivar situações graves como: dores musculares na região dorsal, lombar, pernas, braços e pés; cefaléias; perturbações circulatórias e 
varizes; bursite dos ombros e cotovelos; inflamações de tendões; problemas de coluna com alterações cervicais, dorsais e lombares; fadiga dos olhos e desigualdade da altura dos ombros (PERNAMBUCO, 2001).

Dos participantes do estudo, 72,16\% apresentaram sintomatologia dolorosa indicativa de dor músculo-esquelética, resultados superiores aos 58\% encontrados por Santos Filho e Barreto (2001) em pesquisa realizada com profissionais de Belo Horizonte e inferiores aos $84,2 \%$ encontrados por Lopes et al. (2003) registrados entre profissionais de São Luís - Maranhão.

Entre as regiões que apresentaram alguma dor, desconforto ou dormência as porcentagens obtidas no presente estudo foram: braços - 17,01\%; mãos - 26,29\%; costas - 57,22\% e ombros - 33,51\%. Esses dados confirmam os achados de vários outros autores (LOPES et al., 2003; SANTANA, 1998; SANTOS FILHO; BARRETO, 2001), que descrevem que as regiões mais acometidas são ombro e coluna lombar. Michel-Crosato, Koltiarenko e Biazevic (2006) e Myers e Myers (2004) também relatam em seus estudos a maior porcentagem de profissionais com dores nas costas $(68,3 \%$ e $69,93 \%$ respectivamente).

Condicionamento físico, ginástica laboral, organização mais racional do fluxo de atendimento aos pacientes, reservar um pequeno intervalo entre as consultas a fim de relaxar os músculos e aliviar as tensões inerentes à rotina da profissão podem ser grandes aliados na prevenção de LER e DORT (FRAZÃO, 2000; PERNAMBUCO, 2001; TEREBINTO, 2003).

Do total de participantes, 91,96 \% afirmam valorizar práticas saudáveis no dia-a-dia, fator essencial para a manutenção da qualidade de vida e a prevenção de problemas de saúde em geral, além das LER e DORT. 
Quanto ao tópico gestão em odontologia, a maioria acredita que o conhecimento de processos administrativos para a gestão profissional de equipes é importante, gosta transmitir e discutir informações entre diferentes níveis hierárquicos e tem interesse em adquirir conhecimentos sobre como gerir pessoas. Este dado demonstra a importância do preparo nessa área durante o curso de graduação e pós-graduação e mostra que os profissionais estão cientes que noções de administração e gestão de pessoas podem ser úteis à prática de suas atividades como profissional de saúde.

As cirurgiãs-dentistas responderam perguntas relativas à sua percepção quanto à valorização da mulher. A grande maioria respondeu que é tratada da mesma maneira (72,73\%) e que não sofre discriminação (90,15\%). Uma porcentagem menor considera que é mais valorizada $(5,30 \%)$ e ainda um número que pode ser considerado razoável $(21,97 \%)$ acredita ser menos valorizada por ser do gênero feminino.

Dando sequência à investigação, na tentativa de mensurar a satisfação profissional do grupo estudado por meio da análise dos dados colhidos do questionário de satisfação, puderam ser observados os níveis de satisfação dos cirurgiões-dentistas nos variados blocos e no total, bem como alguns fatores associados. 
Comparando-se (Tabela 5.17) o presente estudo realizado com cirurgiõesdentistas de uma empresa de caráter privado e dados do estudo de Michel-Crosato (2008), com profissionais que trabalham em serviço público (Prefeitura de SP), apesar de sabermos que grande parte trabalha nos dois setores, foram evidenciadas diferenças nos níveis de satisfação: os profissionais da empresa apresentaram média mais alta de satisfação total e em todos os blocos, com exceção de tempo pessoal. Considerando-se que o profissional que se dedica mais horas ao trabalho tem menos tempo para atividades de lazer ou familiares, este achado pode estar relacionado à quantidade de horas trabalhadas: Michel-Crosato encontrou uma média de 37,30 horas trabalhadas por semana, enquanto em nosso estudo a média de horas foi superior (41,08h). Todos os valores de satisfação encontrados também foram, em maior ou menor grau, superiores aos resultados de Jeong et al. (2006).

Tabela 5.17- Distribuição dos Cirurgiões-Dentistas segundo médias de satisfação no trabalho. São Paulo, 2008

Blocos

Presente estudo
Michel-Crosato (2008)

\begin{tabular}{lcc}
\hline Satisfação geral com o trabalho & 3,39 & 2,86 \\
Percepção de renda & 3,21 & 2,71 \\
Tempo pessoal & 2,60 & 2,86 \\
Tempo profissional & 3,13 & 2,79 \\
Equipe & 3,35 & 2,80 \\
Relacionamento com pacientes & 4,34 & 2,77 \\
Fornecimento de assistência/atendimento & 4,16 & 2,25 \\
\hline Todos os blocos & 3,45 & 2,84 \\
\hline
\end{tabular}


Verificando-se as correlações entre algumas variáveis, pôde-se verificar que o gênero foi associado às horas trabalhadas $(p=0,000)$, dor $(p=0,004)$ e relacionamento com pacientes $(p=0,013)$. Os homens trabalham $23 \%$ mais horas que as mulheres analisadas (dados similares aos encontrados por (AYERS et al., 2008; DEL AGUILA et al., 2005; BLASIUS; PAE, 2005); as mulheres apresentaram 30\% maior relato de dor/dormência/ desconforto (semelhante a MICHEL-CROSATO; KOLTIARENKO; BIAZEVIC, 2006; REGIS FILHO; MICHELS; SELL, 2006; SANTOS FILHO; BARRETO, 2001) e os homens apresentaram menor satisfação no relacionamento com pacientes.

As horas trabalhadas foram relacionadas a alguns fatores associados. Houve diferença estatisticamente significante quando as horas foram relacionadas às variáveis gênero $(p=0,000)$, consultório particular $(p=0,002)$, serviço público $(0,000)$, percepção de renda $(0,019)$ e tempo pessoal $(p=0,000)$. Além de os homens trabalharem $23 \%$ mais horas que as mulheres, os dados dessa tabela demonstram que os profissionais que trabalham em consultório particular e serviço público trabalham mais horas do que os que não atuam nesses serviços e quanto maior a quantidade de horas trabalhadas há maior satisfação com relação à percepção de renda e menor satisfação com relação ao tempo pessoal.

Os resultados desta pesquisa poderão colaborar na busca e melhor entendimento das características sociodemográficas e de aspectos relacionados às práticas profissionais, educação continuada e outros fatores que podem influenciar a satisfação profissional e, consequentemente, o desempenho e a qualidade de vida desses indivíduos.

O presente estudo apresenta limitações, visto que foi realizado com um grupo de profissionais que trabalhavam em empresa de caráter privado e a análise foi 
transversal. Mais estudos devem ser conduzidos com outras populações de cirurgiões-dentistas para que se acrescentem novos dados a serem comparados, a fim de se conhecer com maior profundidade o perfil e satisfação profissional da força de trabalho que atua na área atualmente. 


\section{CONCLUSÕES}

Conclui-se, a partir análise dos dados apresentados, que a maioria dos participantes do estudo era do sexo feminino, estudou em faculdade pública, fez curso de especialização, participou de congresso nos 2 anos anteriores, teve acesso a revistas científicas e trabalhava em consultório particular. A maior parte dos profissionais apresentou alguma dor, desconforto ou dormência nos braços, mãos, costas ou ombros nos 12 meses prévios ao estudo. O nível de satisfação total dos cirurgiões-dentistas pôde ser considerado bom, sendo que o bloco que apresentou menor valor de satisfação foi o tempo pessoal. Houve associação do gênero com as variáveis: horas trabalhadas, dor e relacionamento com pacientes e, com relação às horas trabalhadas, houve associação com as variáveis: consultório particular e serviço público. Constatou-se, ainda, que quanto maior a quantidade de horas dedicadas, maior foi a satisfação com relação à renda e menor com relação ao tempo pessoal. 


\section{REFERÊNCIAS ${ }^{1}$}

Alexopoulos EC, Stathi IC, Charizani F. Prevalence of musculoskeletal disorders in dentists. BMC Musculoskelet Disord 2004;5:16.

Ayers KM, Thomson WM, Rich AM, Newton JT. Gender differences in dentists' working practices and job satisfaction. J Dent 2008;36(5):343-50.

Baran RB. Myers Briggs Type Indicator, burnout, and satisfaction in Illinois dentists. Gen Dent 2005;53(3):228-34.

Barbosa ECS, Souza FMB, Cavalcanti AL, Lucas RSCC. Prevalência de distúrbios osteomusculares relacionados ao trabalho em cirurgiões-dentistas de Campina Grande - PB. Pesq Bras Odontoped Clin Integr 2004;4(1):19-24.

Bastos JRM, Aquilante AG, Almeida BS, Lauris JRP, Bijella VT. Análise do perfil profissional de cirurgiões-dentistas graduados na Faculdade de Odontologia de Bauru- USP entre os anos de 1996 e 2000. J Appl Oral Sci 2003;11(4):283-9.

Bengmark D, Nilner M, Rohlin M. Graduates' characteristics and professional situation: a follow-up of five classes graduated from the Malmö model. Swed Dent J 2007;31(3):129-35.

Berthelsen H, Hjalmers K, Söderfeldt B. Perceived social support in relation to work among Danish general dental practitioners in private practices. Eur J Oral Sci 2008;116(2):157-63.

Blasius JJ, Pae EK. Work-pattern differences between male and female orthodontists. Am J Orthod Dentofacial Orthop 2005;128(3):283-91.

Bolin KA, Shulman JD. Nationwide survey of work environment perceptions and dentists' salaries in community health centers. J Am Dent Assoc 2005;136(2):214-20.

Brasil. Ministério da Saúde. Agência Nacional de Vigilância Sanitária. Brasília; 2006.156 p.

Brasil. Ministério da Saúde. Departamento de Ações Programáticas e Estratégicas. Área Técnica de Saúde do Trabalhador. Lesões por esforços repetitivos (LER) e distúrbios osteomusculares relacionados ao trabalho (DORT). Brasília; 2001. 36 p. 
Brennan DS, Spencer AJ, Szuster FS. Service provision patterns by main diagnoses and characteristics of patients. Community Dent Oral Epidemiol 2000;28(3):225-33.

Cabral ED, Caldas Jr AF, Cabral HAM. Influence of the patient's race on the dentist's decision to extract or retain a decayed tooth. Community Dent Oral Epidemiol 2005; 33(6):461-6.

Cordón J. Estudos sobre a força de trabalho em saúde bucal: características do cirurgião-dentista no Distrito Federal. Divulgação Saúde em Debate 1991;6(10):19-26.

Costa B. Do ensino a prática odontológica: mito ou realidade na Grande São Paulo [Tese de Doutorado]. São Paulo: Faculdade de Odontologia da USP; 1988.

Costa SM, Durães SJA, Abreu MHNG. Feminização do curso de odontologia da Universidade Estadual de Montes Claros - UNIMONTES, Brasil. Rev C S Col [periódico on line]; 2009 jan. Disponível em: URL:

http://www.cienciaesaudecoletiva.com.br [2009 mar 10].

del Aguila MA, Leggott PJ, Robertson PB, Porterfield DL, Felber GD. Practice patterns among male and female general dentists in a Washington State population. J Am Dent Assoc 2005;136(6):790-6.

D'Ávila S, Oliveira PAP, Lucas RSCC, Souza EA. Assistência Odontológica X Plano de Saúde: um estudo em Campina Grande, Paraíba, Brasil. Pesq Bras Odontoped Clin Integr 2007;7(3):259-63.

Frazão P. Dores do ofício. Revista da ABO Nacional 2000;8(1):8-10.

Gilmour J, Stewardson DA, Shugars DA, Burke FJ. An assessment of career satisfaction among a group of general dental practitioners in Staffordshire. Br Dent J 2005;198(11):701-4.

Gorter RC, Te Brake JH, Eijkman MA, Hoogstraten J. Job resources in Dutch dental practice. Int Dent J 2006;56(1):22-8.

Gorter RC, Te Brake HJ, Hoogstraten J, Eijkman MA. Positive engagement and job resources in dental practice. Community Dent Oral Epidemiol 2008;36(1):47-54. 
Graça CC, Araújo TM, Silva CEP. Prevalência de dor musculoesquelética em cirurgiões dentistas. Rev Baiana de Saúde Pública 2006;30(1):59-76.

Haddad S. A Educação Continuada e as políticas públicas no Brasil. REVEJ@ - Rev Educ Jovens e Adultos 2007;1(1):1-113.

Hakanen JJ, Bakker AB, Demerouti E. How dentists cope with their job demands and stay engaged: the moderating role of job resources. Eur J Oral Sci 2005;113(6):479-87.

Harris MJ, Zwane NP. Expectations and perceptions of professional satisfaction in a cohort of Medunsa dental graduates in compulsory community service. SADJ 2005;60(10):438, 440, 442.

Harris RV, Ashcroft A, Burnside G, Dancer JM, Smith D, Grieveson B. Facets of job satisfaction of dental practitioners working in different organisational settings in England. Br Dent J 2008;204(1):16-7.

Hjalmers K. Good work for dentists--ideal and reality for female unpromoted general practice dentists in a region of Sweden. Swed Dent J Suppl 2006;(182):10-136.

Hjalmers K, Söderfeldt B, Axtelius B. Moral values and career: factors shaping the image of healthy work for female dentists. Acta Odontol Scand 2006;64(5):255-61.

Instituto Brasileiro de Estudos e Pesquisas Socioeconômicas. O perfil do cirurgiãodentista no Brasil [pesquisa realizada para entidades nacionais de odontologia: $A B O$, ABENO, ACBO, CFO, FIO e FNO. 2003. Disponível em: URL: http://www.cfo.org.br/download/perfil CD.pdf [ 2008 mar. 06].

Instituto Nacional de Estudo e Pesquisa Educacionais. 2000. Odontologia é mercado promissor para estudante. Disponível em: URL: http//www.inep.gov.br [2009 fev. 10].

Jeong SH, Chung JK, Choi YH, Sohn W, Song KB. Factors related to job satisfaction among South Korean dentists. Community Dent Oral Epidemiol 2006;34(6):460-6.

Koltiarenko A. Prevalência de distúrbios osteomusculares dos cirurgiões-dentistas do Meio-Oeste Catarinense, 2005 [Dissertação de Mestrado]. Santa Catarina:

Faculdade de Odontologia da UNOESC; 2005. 
Lopes FF, Pereira FTF, Oliveira AEF, Spyrides KS. Prevalência dos distúrbios osteomusculares relacionados ao trabalho em cirurgiões-dentistas de São Luís MA. São Paulo: Sociedade Brasileira de Pesquisa Odontológica; 2003, p. 227.

Luzzi L, Spencer AJ, Jones K, Teusner D. Job satisfaction of registered dental practitioners. Aust Dent J 2005;50(3):179-85.

Madeira MC, Perri De Carvalho AC. Necessidades e tendências da odontologia nas faculdades e no exercício da profissão. A proposta de uma enquete. Rev APCD 1980;34(4):284-93.

Marziale MHP, Mendes IAC. O investimento em pesquisas na área da saúde: termos de referência para o desenvolvimento científico e técnológico brasileiro. Rev LatinoAm Enfermagem 2006;14(2):149-50 [periódico on line]. Disponível em: URL: http://www.scielo.br/rlae [2009 fev. 09].

McEwen EM, Seward MH. The contribution of women to dentistry in the $1980 \mathrm{~s}$. $\mathrm{Br}$ Dent J 1988;5(11):339-41.

Michel-Crosato E. Perfil da força de trabalho representada pelo Cirurgião-Dentista: análise epidemiológica dos profissionais que exerciam suas atividades na Prefeitura Municipal de São Paulo, 2007 [Tese de Livre-Docência]. São Paulo: Faculdade de Odontologia da USP; 2008.

Michel-Crosato E, Calvielli ITP, Biazevic MGH, Crosato E. Perfil da força de trabalho representada pelos egressos da FOUSP (1990-1998). RPG Rev Pós Grad 2003;10(3):217-23.

Michel-Crosato E, Koltiarenko A, Biazevic MGH. Prevalência de distúrbios osteomusculares em cirurgiões-dentistas. Odontologia e Sociedade 2006;8(1):89.

Michelin CF, Loureiro CA. Estudo epidemiológico dos distúrbios musculoesqueletais e ergonômicos em cirurgiöes-dentistas. RFO UPF 2000;5(2):61-7.

Moimaz SAS. Estudo sobre o perfil profissional dos cirurgiões-dentistas formados pela Faculdade de Odontologia de Araçatuba - UNESP, no período de 1989 a 1999 [Tese de Livre-Docência]. Araçatuba: Faculdade de Odontologia da UNESP; 2003.

Moimaz SAS, Saliba NA, Blanco MRB. A força do trabalho feminino na odontologia, em Araçatuba - SP. J Appl Oral Sci 2003;11(4):301-5. 
Myers HL, Myers LB. 'It's difficult being a dentist': stress and health in the general dental practitioner. Br Dent J 2004;197(2):89-93.

Naidoo S. Women in dentistry in South Africa: a survey of their experiences and opinions. SADJ 2005;60(7):284, 286, 288.

Newton JT, Thorogood N, Gibbons DE. The work patterns of male and female dental practitioners in the United Kingdom. Int Dent J 2000;50(2):61-8.

Nicolielo J, Bastos JRM. Satisfação profissional do cirurgião-dentista conforme tempo de formado. Rev Fac Odontol de Bauru 2002;10(2):69-74.

Oppenheim AM. Questionnaire design, interviewing and attitude measurement. London: Pinter; 1993.

Parajara F. A caminho da igualdade. Rev APCD 2000;54(1):11-9.

Pereira, FTF, Lopes FF, Oliveira AEF, Spyrides, KS. Distúrbios osteomusculares relacionados ao trabalho entre os cirurgiões-dentistas especialistas e generalistas. Rev Bras Odontol 2004;61(3/4):213-6.

Pernambuco. Secretaria Estadual de Saúde. Manual de biossegurança no atendimento odontológico. Pernambuco; 2001. 126 p.

Perri De Carvalho AC. Educação \& saúde em odontologia: ensino da prática, prática no ensino. São Paulo: Santos; 1995a.

Perri De Carvalho AC. O ensino e o exercício da odontologia na Alta Noroeste do Estado de São Paulo. São Paulo: Nupes/USP; 1995b.

Pilgård G, Söderfeldt B, Hjalmers K, Rosenquist J. Dimensions of good work for employees in oral and maxillofacial surgery in Sweden. Swed Dent J 2007;31(3):147-54.

Pinto VG. Saúde bucal coletiva. 5ª ed. São Paulo: Santos; 2008.

Pourat N, Roby DH, Wyn R, Marcus M. Characteristics of dentists providing dental care to publicly insured patients. J Public Health Dent 2007;67(4):208-16. 
Puriene A, Petrauskiene J, Janulyte V, Balciuniene I. Factors related to job satisfaction among Lithuanian dentists. Stomatologija 2007;9(4):109-13.

Regis Filho, GI, Michels G, Sell I. Lesões por esforços repetitivos/distúrbios osteomusculares relacionados ao trabalho em cirurgiões-dentistas. Rev Bras Epidemiol 2006;9(3):346-59.

Roth SF, Heo G, Varnhagen C, Glover KE, Major PW. Job satisfaction among Canadian orthodontists. Am J Orthod Dentofacial Orthop 2003;123:695-700.

Santana EJB. Estudo epidemiológico de lesões por esforços repetitivos em cirurgiões-dentistas em Salvador Bahia. Revista da FOUFBA 1998;18(1):59-63.

Santos LFT, Peloggia MC. Conhecimentos, atitudes e comportamento frente aos riscos operacionais dos cirurgiões-dentistas do Vale do Paraíba. Rev Biociênc 2002;8(1):85-93.

Santos Filho SB, Barreto SM. Atividade ocupacional e prevalência de dor osteomuscular em cirurgiões-dentistas de Belo Horizonte, Minas Gerais, Brasil: contribuição ao debate sobre os distúrbios osteomusculares relacionados ao trabalho. Cad de Saúde Pública 2001;17(1):181-93.

Serpa D. O assédio feminino à profissão. Rev APCD 1991;1(1):12-4.

Silva SRC. Características dos cirurgiões-dentistas com vínculo empregatício, em empresas públicas e/ou privadas no município de Araraquara - SP [Dissertação de Mestrado]. São Paulo: Faculdade de Saúde Pública da USP; 1994.

Te Brake H, Bouman AM, Gorter R, Hoogstraten J, Eijkman M. Professional burnout and work engagement among dentists. Eur J Oral Sci 2007;115(3):180-5.

Terebinto CG. LER/DORT - Aspectos jurídicos e sociais - Necessidade de prevenção [artigos doutrinários]; 2003. Disponível em: URL:

http://www.prt21.mpt.gov.br/fepmat/artigo 01.htm [2008 abr 15].

Toledo F, Milioni B. Dicionário de recursos humanos. 3ª ed. São Paulo: Atlas; 1986. 
Apêndice A - Termo de consentimento livre e esclarecido

Título do estudo: Satisfação Profissional: perfil dos cirurgiões-dentistas que exercem suas atividades em empresa do setor privado - São Paulo, 2008

Pesquisador(es) responsável(is): Teresa Maria da Ponte Instituição/Departamento: FOUSP/ Departamento de Odontologia Social Telefone para contato: 6523 9347/ 94261986

A odontologia tem passado por profundas modificações nas últimas décadas e vários fatores têm contribuído para essas alterações. Dentre eles, podemos destacar a mudança do sistema de saúde brasileiro, a popularização dos sistemas de odontologia em grupo, a abertura de novos cursos na área, a maior oferta de profissionais no mercado de trabalho e a diminuição do poder aquisitivo da população. Tais fatores, além de estarem mudando o perfil da atividade odontológica, têm feito com que o mercado de trabalho também se modifique, o que implica alterações na força de trabalho que se dedica a essa profissão.

Tendo em vista o maior conhecimento da realidade da profissão em nosso país, é de suma importância e é o objetivo desse estudo verificar se essas alterações estão de fato modificando o exercício profissional, o perfil dos cirurgiões-dentistas, o tipo de serviço oferecido, a remuneração profissional, o número de horas trabalhadas e o nível de satisfação profissional, a fim de avaliar a força de trabalho que milita na área.

- Você está sendo convidado(a) a responder às perguntas deste questionário de forma totalmente voluntária.

- Antes de concordar em participar desta pesquisa e responder este questionário, é muito importante que você compreenda as informações e instruções contidas neste documento.

- Os pesquisadores deverão responder todas as suas dúvidas antes de você se decidir a participar.

- Você tem o direito de desistir de participar da pesquisa a qualquer momento, sem nenhuma penalidade e sem perder os benefícios aos quais tenha direito. 
Objetivo do estudo: O presente estudo tem por objetivo verificar o perfil da força de trabalho de um grupo de profissionais representado pelos cirurgiões-dentistas que desenvolvem suas atividades em uma empresa do setor privado.

Procedimentos. Sua participação nesta pesquisa consistirá apenas no preenchimento deste questionário, respondendo às perguntas formuladas.

Benefícios. Esta pesquisa trará maior conhecimento sobre o tema abordado, sem benefício direto para você.

Riscos. O preenchimento deste questionário não representará qualquer risco de ordem física ou psicológica para você.

Sigilo. As informações fornecidas por você serão confidenciais e de conhecimento apenas dos pesquisadores responsáveis. Os sujeitos da pesquisa não serão identificados em nenhum momento, mesmo quando os resultados desta pesquisa forem divulgados em qualquer forma.

$\mathrm{Eu}$,

RG_, certifico que li as informações, sendo suficientemente esclarecido(a) sobre o estudo e autorizo a realização do mesmo com a minha colaboração espontânea.

de de 2008.

Assinatura do participante 
O presente questionário faz parte da pesquisa que tem como objetivo verificar a satisfação profissional dos cirurgiões-dentistas. Os dados coletados são confidenciais e as instituições empregadoras não terão acesso. A pesquisa faz parte de uma série de ações do Observatório de Recursos Humanos em Saúde Bucal da Universidade de São Paulo.

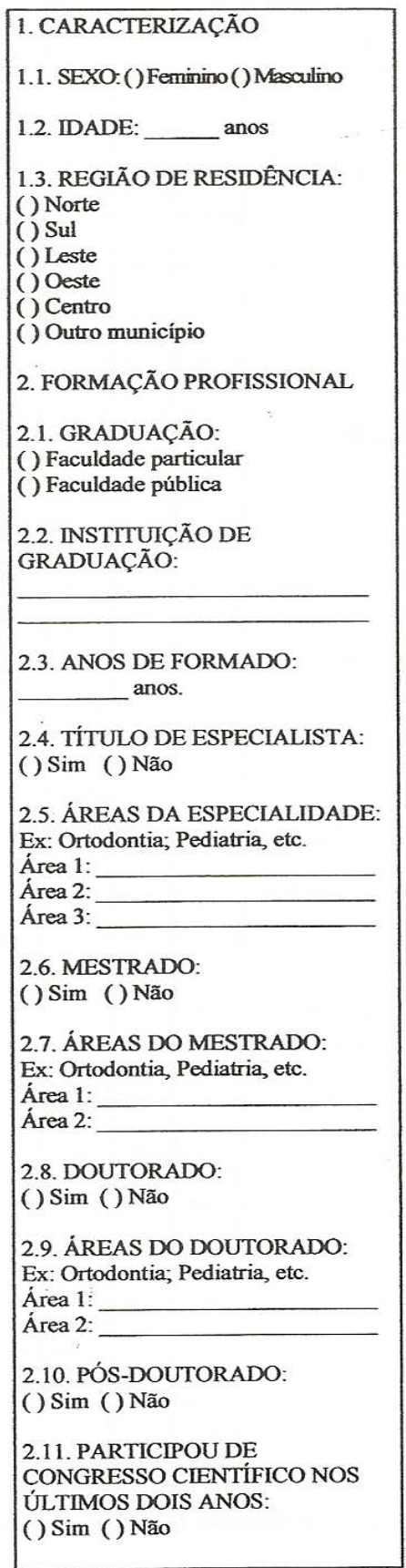

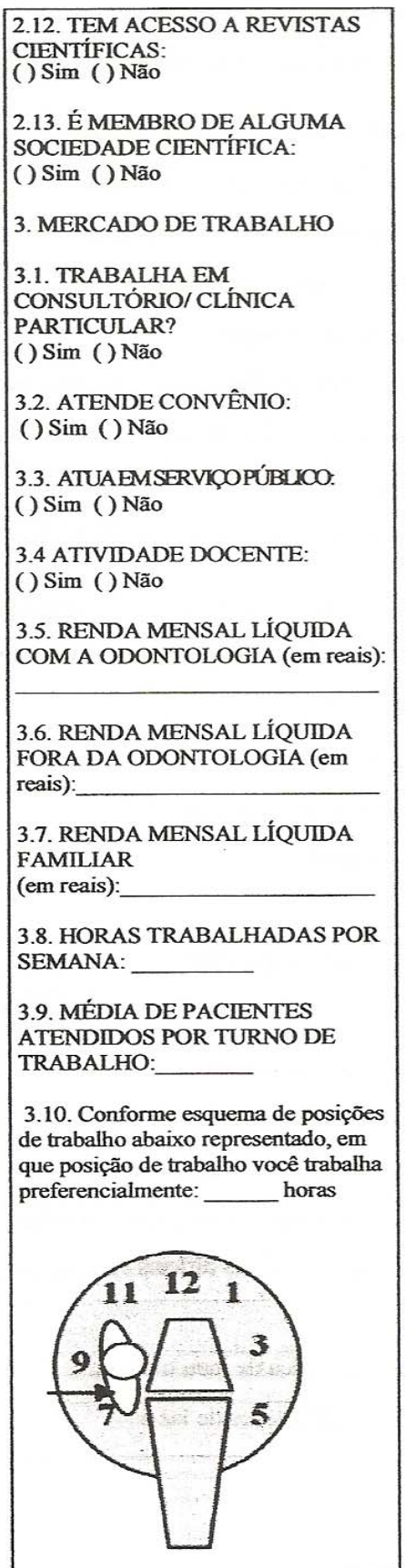

3.11. Considerando os últimos 12 meses, você tem tido algum problema (tal como dor, desconforto ou dormência) nas seguintes regiões: () Braços

() Mãos

() Costas

() Ombro

4. GESTÃO EM ODONTOLOGIA

4.1 Eu acho importante o

conhecimento de processos

administrativos para a gestão

profissional de equipes.

() Sim () Não

4.2 Gosto de ser mediador, transmitindo e discutindo informações entre diferentes níveis hierárquicos. ( ) Sim () Não

4.3 Tenho interesse em adquirir conhecimentos sobre como gerir pessoas (gestão de recursos humanos).

( ) $\operatorname{Sim}($ ) Não

\section{PRÁTICAS SAUDÁVEIS}

5.1 Valorizo práticas saudáveis no dia-a-dia.

( ) $\operatorname{Sim}$ ( ) Não

6. PARTICIPAÇÃO DA MULHER NA ODONTOLOGIA

(apenas para participantes do sexo feminino)

6.1 A mulher em relação ao homem no exercício profissional:

( ) é mas valorizada

() é tratada da mesma maneira

() é menos valorizada

6.2 Você, como profissional, sofre discriminação:

() $\mathrm{Sim}$

( ) Não

6.3 Quais são as principais dificuldades da mulher no exercício profissional: 
7. Indicador de Satisfação Profissional (considere todas as suas atividades relacionadas à Odontologia)

\begin{tabular}{|c|c|c|c|c|c|}
\hline Preencha: de 1 (Discordo fortemente) a 5 (Concord & 1 & 2 & 3 & 4 & 5 \\
\hline \multicolumn{6}{|c|}{$\begin{array}{l}\text { 1. Eu tenho pouquíssimo tempo para me manter atualizado a respeito dos avanços na área de } \\
\text { odontologia }\end{array}$} \\
\hline \multicolumn{6}{|l|}{ 2. Minha renda permite que eu sustente minha família muito bem } \\
\hline \multicolumn{6}{|c|}{$\begin{array}{l}\text { 3. Eu estou tecnicamente preparado para lidar com os problemas odontológicos de meus } \\
\text { pacientes }\end{array}$} \\
\hline \multicolumn{6}{|l|}{ 4. Tenho tempo suficiente para melhorar minhas habilidades clínicas } \\
\hline \multicolumn{6}{|l|}{ 5. A odontologia preenche minhas atuais aspirações com a carreira } \\
\hline \multicolumn{6}{|l|}{ 6. Gostaria de deixar o meu emprego/trabalho para fazer outra coisa } \\
\hline \multicolumn{6}{|l|}{ 7. Tenho suficiente tempo disponivel para minha vida pessoal } \\
\hline \multicolumn{6}{|l|}{ 8. A qualidade de meu pessoal auxiliar deixa a desejar } \\
\hline \multicolumn{6}{|c|}{ 9. Eu pareço mais satisfeito/a com meu trabalho/emprego do que realmente estou } \\
\hline 10. Comparado a outros dentistas, meus ganhos totais são muito me & & & & & \\
\hline \multicolumn{6}{|l|}{ 11. Relacionar-me com pacientes, para mim, é muito frustrante } \\
\hline \multicolumn{6}{|c|}{$\begin{array}{l}\text { 12. Sabendo o que eu sei hoje, eu teria tomado a mesma decisão de fazer odontologia } \\
\text { novamente }\end{array}$} \\
\hline \multicolumn{6}{|c|}{ 13. Eu perco oportunidades de fornecer assistência/atendimento de qualidade } \\
\hline \multicolumn{6}{|c|}{ 14. A odontologia é a área onde eu posso oferecer minha melhor contribuição profissional } \\
\hline \multicolumn{6}{|l|}{ 15. Tenho tempo suficiente para atividades de lazer } \\
\hline \multicolumn{6}{|l|}{ 16. Eu não gosto de interagir com meus pacientes } \\
\hline \multicolumn{6}{|l|}{ 17. Em geral, estou extremamente satisfeito com minha carreira } \\
\hline \multicolumn{6}{|l|}{ 18. O rendimento de meus auxiliares é excelente } \\
\hline \multicolumn{6}{|l|}{ 19. A equipe da clínica trabalha bem em conjunto } \\
\hline \multicolumn{6}{|l|}{ 20. Sinto-me limitado em minha posição / meu cargo atual } \\
\hline \multicolumn{6}{|c|}{$\begin{array}{l}\text { 21. A renda que recebo de minha prática é, na maior parte das vezes, satisfatória para minhas } \\
\text { necessidades }\end{array}$} \\
\hline \multicolumn{6}{|c|}{ 22. Tenho tempo suficiente para contatos profissionais com colegas } \\
\hline \multicolumn{6}{|l|}{ 23. Minha renda não é, nem de perto, tão alta quanto à de outros dentistas } \\
\hline \multicolumn{6}{|l|}{ 24. A qualidade da assistência interpessoal que eu ofereço é muito alta } \\
\hline \multicolumn{6}{|c|}{ 25. Minha renda pode ser comparada favoravelmente à de outros dentistas } \\
\hline \multicolumn{6}{|c|}{ 26. Tenho oportunidades muito limitadas de discutir casos dificeis com colegas } \\
\hline \multicolumn{6}{|l|}{ 27. Eu gosto de ajudar meus pacientes } \\
\hline \multicolumn{6}{|l|}{ 28. Eu tenho muita satisfação com a qualidade técnica de meu trabalho } \\
\hline 29. Tempo pouquíssimo tempo disponível para atividades de lazer & & & & & \\
\hline
\end{tabular}




\title{
ANEXO A - Parecer do Comitê de Ética em Pesquisa
}

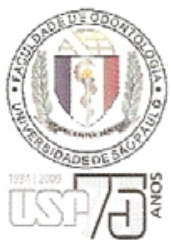

\author{
Universidade de São Paulo \\ Faculdade de Odontologia \\ Comitê de Ética em Pesquisa
}

\section{PARECER DE APROVAÇÃO \\ FR - 216075 \\ Protocolo 140/08}

Com base em parecer de relator, o Comitê de Ética em Pesquisa APROVOU o protocolo de pesquisa: "Perfil dos Cirurgiões-Dentistas que exercem suas atividades em Empresa do Setor Privado. São Paulo, 2008", de responsabilidade do Pesquisador Teresa Maria da Ponte, sob orientação do(a) da Prof. Dr. Edgard Michel Crosato.

Tendo em vista a legislação vigente, devem ser encaminhados a este Comitê relatórios anuais referentes ao andamento da pesquisa e ao término cópia do trabalho em "cd". Qualquer emenda do projeto original deve ser apresentada a este CEP para apreciação, de forma clara e sucinta, identificando a parte do protocolo a ser modificada e suas justificativas.

São Paulo, 17 de fevereiro de 2009.

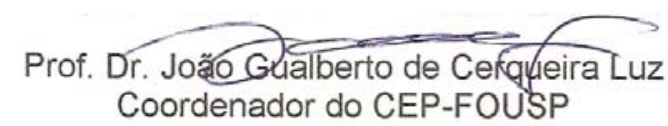

